\title{
Mechanistic insights into the protective roles of polyphosphate against amyloid cytotoxicity
}

\author{
Justine Lempart ${ }^{1,2}$, Eric Tse ${ }^{3}$, James A Lauer ${ }^{2}$, Magdalena I Ivanova ${ }^{4,5}$ (D), Alexandra Sutter ${ }^{4}$ (D) Nicholas Yoo ${ }^{2}$, \\ Philipp Huettemann², Daniel Southworth ${ }^{3}$, Ursula Jakob², ${ }^{2,6}$
}

\begin{abstract}
The universally abundant polyphosphate (polyP) accelerates fibril formation of disease-related amyloids and protects against amyloid cytotoxicity. To gain insights into the mechanism(s) by which polyp exerts these effects, we focused on $\alpha$-synuclein, a well-studied amyloid protein, which constitutes the major component of Lewy bodies found in Parkinson's disease. Here, we demonstrate that poly $P$ is unable to accelerate the rate-limiting step of $\alpha$-synuclein fibril formation but effectively nucleates fibril assembly once $\alpha$-synuclein oligomers are formed. Binding of polyP to $\alpha$-synuclein either during fibril formation or upon fibril maturation substantially alters fibril morphology and effectively reduces the ability of $\alpha$-synuclein fibrils to interact with cell membranes. The effect of polyP appears to be $\alpha$-synuclein fibril specific and successfully prevents the uptake of fibrils into neuronal cells. These results suggest that altering the polyp levels in the extracellular space might be a potential therapeutic strategy to prevent the spreading of the disease.
\end{abstract}

DOI 10.26508/lsa.201900486 | Received 16 July 2019 | Revised 9 September 2019 | Accepted 10 September 2019 | Published online 18 September 2019

\section{Introduction}

Parkinson's disease (PD), the second most common neurodegenerative disorder known (de Lau et al, 2004), is characterized by a loss of dopaminergic neurons in the substantia nigra (Rinne et al, 1989; Damier et al, 1999). A hallmark of the disease is the appearance of intracellular protein inclusions (i.e., Lewy bodies), which consist primarily of insoluble fibrils of $\alpha$-synuclein, a 140amino acid protein involved in presynaptic vesicle formation (Goedert, 2001; Shults, 2006). Although it is now well established that deposition of $\alpha$-synuclein fibrils associates with the disease and that cell death can be elicited simply by incubating neuronal cells with $\alpha$-synuclein fibrils (Winner et al, 2011), many open questions remain concerning the mechanism of toxicity, the structural features of the toxic $\alpha$-synuclein species, and the way(s) by which $\alpha$-synuclein toxicity propagates in the brain.

In solution, $\alpha$-synuclein is a soluble monomer with extensive regions of intrinsic disorder (Fakhree et al, 2018). In vitro studies demonstrated that upon prolonged incubation, $\alpha$-synuclein monomers undergo conformational rearrangements, which lead to the formation of aggregation-sensitive oligomers (Conway et al, 2000b). These nuclei are capable of sequestering other $\alpha$-synuclein monomers and will grow into protofibrils and eventually into insoluble, protease-resistant fibrils (Wood et al, 1999; Conway et al, 2000a). In vitro, the rate-limiting step in fibril formation appears to be the formation of the initial nuclei, and fibril formation has been shown to be accelerated by the addition of negatively charged polymers, including glucosaminoglycans (i.e., heparin) (Cohlberg et al, 2002), RNA (Munishkina et al, 2009), or phospholipids (Zhu et al, 2003). The precise roles that these additives play in in vivo fibril formation remain to be determined.

Recent studies provided supporting evidence that amyloid toxicity is not caused by the fibrils per se but by oligomeric species that transiently accumulate on the pathway to fibril formation (Winner et al, 2011; Chen et al, 2015). These oligomers, which have been shown to affect mitochondrial function (Luth et al, 2014), membrane permeability (Lashuel et al, 2002; Tsigelny et al, 2012), and/or the cytoskeleton (Roberts \& Brown, 2015), are thought to be responsible for the observed neuroinflammation (Lee et al, 2010) and cell death (Winner et al, 2011). Moreover, amyloid oligomers seem to be the primary species that spread among cells (Danzer et al, 2009, 2012) and to be responsible for the prion-like propagation of PD pathology (Li et al, 2008; Desplats et al, 2009). Cell-to-cell transmission appears to involve the active secretion of $\alpha$-synuclein oligomers into the extracellular space followed by the uptake of the amyloids into neighboring recipient cells via micropinocytosis and glycosaminoglycan receptors (Holmes et al, 2013; Reyes et al, 2015; Gustafsson et al, 2018). Experiments conducted in cell culture confirmed that $\alpha$-synuclein oligomers can readily spread between neurons and glial cells (Hansen et al, 2011; Domert et al, 2016), and, once taken up by recipient cells, sequester monomeric $\alpha$-synuclein into insoluble foci (Reyes et al, 2015; Rostami et al, 2017).

\footnotetext{
${ }^{1}$ Graduate Program in Biochemistry, Department of Chemistry, Technische Universität München, München, Germany ${ }^{2}$ Department of Molecular, Cellular and Developmental Biology University of Michigan, Ann Arbor, MI, USA ${ }^{3}$ Institute for Neurodegenerative Diseases, Department of Biochemistry and Biophysics, University of California, San Francisco, CA, USA ${ }^{4}$ Biophysics Program, University of Michigan, Ann Arbor, MI, USA ${ }^{5}$ Department of Neurology, University of Michigan, Ann Arbor, MI, USA ${ }^{6}$ Department of Biological Chemistry, University of Michigan, Ann Arbor, MI, USA
} 
Recent work from our laboratory demonstrated that polyphosphate (polyP), a highly conserved and universally present polyanion, significantly decreases the cytotoxicity of amyloidogenic proteins (Cremers et al, 2016). These results were corroborated in studies with amyloid $\beta_{25-35}$, which showed that preincubation of PC12 cells or primary cortical neurons with polyP protects against the neurotoxic effects of the peptide (Muller et al, 2017). In vitro studies revealed that polyP substantially accelerates $\alpha$-synuclein fibril formation in a chain length-dependent manner, causing the formation of both shedding-resistant and seeding-deficient polyPassociated fibrils (Cremers et al, 2016). Localization studies revealed that polyP, such as $\alpha$-synuclein, is both secreted and taken up by neuronal cells and, hence, localizes both inside and outside of cells (Angelova et al, 2018). These results raised intriguing questions as to what $\alpha$-synuclein species interact with polyP, how premature fibril formation might be avoided, and, most importantly, by what mechanism polyP is able to protect neuronal cells against $\alpha$-synuclein toxicity.

Here, we show that polyP does not interact with monomeric $\alpha$-synuclein but effectively nucleates $\alpha$-synuclein fibril formation once prefibrillar species are present. PolyP causes pronounced morphological changes in both de novo forming fibrils as well as upon its addition to mature $\alpha$-synuclein fibrils, demonstrating that $\alpha$-synuclein fibrils are inherently dynamic and amendable to polypmediated structural changes. Importantly, presence of polyP strongly interferes with the interaction of $\alpha$-synuclein fibrils with cell membranes and prevents the uptake of $\alpha$-synuclein fibrils into differentiated neuroblastoma cells. These results explain the cytoprotective effect of polyP and suggest that extracellular polyP might be able to influence the spreading of this disease.

\section{Results}

\section{PolyP accelerates fibril formation by nucleating $\alpha$-synuclein oligomers}

Amyloid fibril formation is most commonly monitored by measuring the fluorescence of thioflavin T (ThT), a small molecular dye that becomes highly emissive when intercalated into the $\beta$-sheets of amyloidogenic oligomers and fibrils (LeVine, 1999). ThT kinetics of amyloid fibril formation can be divided into three distinct phases (Fig 1A): the nucleation (i.e., lag) phase, in which soluble monomers undergo structural changes and nucleate; the elongation (i.e., growth) phase, during which ThT-positive oligomers and protofibrils form; and the equilibration (i.e., plateau) phase, in which mature fibrils undergo cycles of shedding and seeding (Shoffner \& Schnell, 2016).

Consistent with previous polyP titrations (Cremers et al, 2016), we found that the presence of $500 \mu \mathrm{M}$ polyP substantially accelerates
A
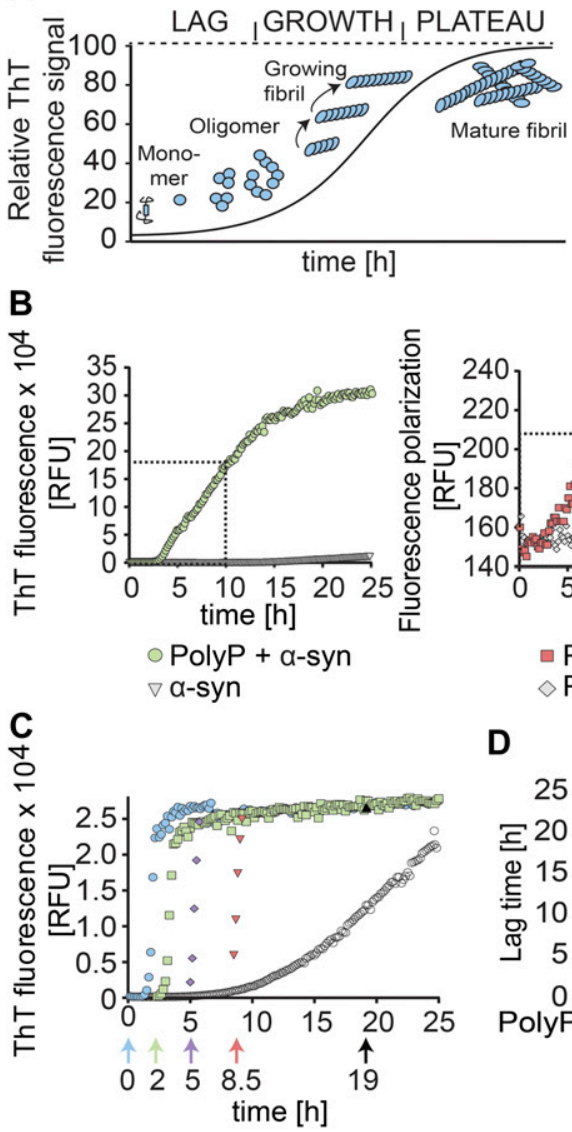

Figure 1. Influence of polyP on $\alpha$-synuclein fibril formation in vitro.

(A) Model of the amyloid-fibril forming process using ThT-fluorescence. (B) $100 \mu \mathrm{M}$ freshly prepared $\alpha$-synuclein was incubated in the absence or presence of $500 \mu \mathrm{M}$ fluorescently labeled polyP $\mathrm{P}_{300-A F 647}$ (in $\mathrm{P}_{\mathrm{i}}$ units) at $37^{\circ} \mathrm{C}$ under constant stirring. ThT fluorescence was used to monitor fibril formation (left panel), and FP experiments were conducted to measure binding of poly $\mathrm{P}_{300-\mathrm{AF} 647}$ to $\alpha$-synuclein (middle panel). Overlay of normalized ThT and FPcurves (right panel). Data are the mean of three independent experiments \pm SD. (C) Addition of $500 \mu \mathrm{M}$ polyP (in $\mathrm{P}_{\mathrm{i}}$ units) before (cyan circles) or at defined time points during the fibril-forming process of $300 \mu \mathrm{M}$ $\alpha$-synuclein. ThT fluorescence was monitored. All experiments were conducted at least three times. Representative kinetic traces are shown. (D) Influence of different poly $\mathrm{P}_{300}$ and $\alpha$-synuclein concentrations on the lag phase of fibril formation. ThT fluorescence was monitored and the lag phase was determined. The mean of four experiments \pm SD is shown. Source data are available for this figure.

$$
\begin{aligned}
& \backsim \text { PolyP + a-syn } \\
& \diamond \text { PolyP }
\end{aligned}
$$

D

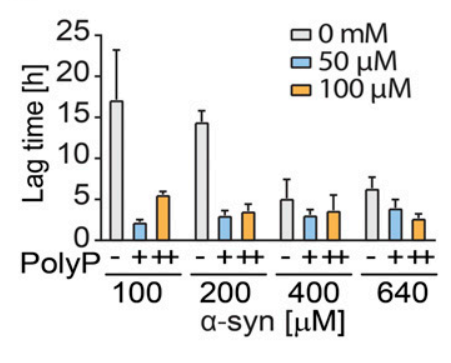


the fibril-forming process of $\alpha$-synuclein, both by shortening the lag phase and by increasing the rate of fibril growth (Fig 1B and C). To determine when during the polymerization process polyP acts on amyloidogenic proteins, we conducted fluorescence polarization (FP) measurements, which record the tumbling rate of fluorescent molecules as readout for real-time binding events (Rossi \& Taylor, 2011). We labeled poly $P_{300}$-chains (molecular weight [MW]: $30 \mathrm{kD}$ ) with Alexa Fluor 647 (polyP 300-AF647) $_{3}$ and conducted FP measurements in the presence of freshly prepared $\alpha$-synuclein (MW: $14 \mathrm{kD}$ ) for $40 \mathrm{~h}$ (Fig 1B, middle panel). Unexpectedly, we did not observe any significant increase in the FP signal over the first $\sim 2.5 \mathrm{~h}$ of incubation, suggesting that polyP does not interact with monomeric $\alpha$-synuclein. After this lag-phase, however, the FP signal rapidly increased and reached an apparent plateau after about $12 \mathrm{~h}$ of incubation (Fig 1B, middle panel). Because we could not exclude that the plateau was not due to the size of the polyP-fibril complexes reaching the upper limit of our polarization measurements, we only directly compared the first $10 \mathrm{~h}$ of ThT binding and anisotropy measurements. Overlay of the normalized data revealed that although the lag phase in the FP measurement was slightly shorter than the lag phase in the ThT measurements, the rate of signal increase was very similar (Fig 1B, right panel). These results suggested that polyP does not interact with $\alpha$-synuclein species that occur early in the fibril-forming process (i.e., monomers) but instead binds $\alpha$-synuclein species shortly before or concomitant with their ability to intercalate ThT.

Time-delayed polyP addition experiments confirmed these results and demonstrated that polyP acts on nucleation-competent oligomers and/or protofibrils. For these studies, we used experimental conditions under which $\alpha$-synuclein fibril formation proceeds with a lag phase of $\sim 6 \mathrm{~h}$ in the absence and $\sim 1.5 \mathrm{~h}$ in the presence of polyP (Fig 1C, compare open and cyan circles). When we added polyP $2 \mathrm{~h}$ after the start of the incubation, the lag phase was reduced from the remaining $4 \mathrm{~h}$ in the absence of polyP to less than 30 min (Fig $1 C$, green squares). Addition of polyP after $5 \mathrm{~h}$ caused an immediate increase in ThT signal (Fig 1C, blue diamonds), whereas addition of polyP mid-way through the elongation phase of $\alpha$-synuclein fibril formation triggered maximal ThT binding within less than 10 min (Fig $1 C$, red triangles). These results strongly suggested that polyP binds to a range of presumably non-monomeric $\alpha$-synuclein species and supports their association into insoluble fibrils.

\section{PolyP does not affect rate-limiting step of fibril formation}

Our finding that polyP does not detectably interact with $\alpha$-synuclein monomers but readily stimulates fibril formation once ThT-positive oligomers have formed, suggested that polyP does not affect the rate-limiting step of $\alpha$-synuclein fibril formation. To test this idea, we combined increasing $\alpha$-synuclein concentrations with increasing polyP concentrations and measured the respective lag phase of fibril formation using ThT fluorescence (Fig 1D). As expected, increasing the $\alpha$-synuclein concentration from 100 to 400 $\mu \mathrm{M}$ in the absence of polyP reduced the lag phase from about $16 \mathrm{~h}$ to less than $7 \mathrm{~h}$. Higher concentrations of $\alpha$-synuclein (i.e., $640 \mu \mathrm{M}$ ) did not significantly shorten the lag phase any further. The presence of physiological relevant concentrations of poly $\mathrm{P}_{300}(50 \mu \mathrm{M}$ in $\mathrm{P}_{\mathrm{i}}$-units) (Kumble \& Kornberg, 1995; Holmstrom et al, 2013) reduced this lag time to 2-3 h. Noteworthy, this reduction in lag time appeared to be independent of the $\alpha$-synuclein concentration used (Fig 1D). Moreover, doubling the polyP concentration also failed to further reduce the lag phase. These results agreed with previous results showing that $\alpha$-synuclein undergoes conformational changes and/or oligomerization processes that are rate limiting (Wood et al, 1999; Krishnan et al, 2003) and suggested that this step cannot be accelerated by the presence of polyP. We concluded from these results that simple co-existence of polyP and $\alpha$-synuclein in the same (extra)cellular compartment will unlikely be sufficient to trigger de novo fibril formation.

\section{PolyP alters morphology of preformed $\alpha$-synuclein fibrils}

FP-binding studies using preformed $\alpha$-synuclein fibrils revealed that polyP not only interacts with ThT-positive oligomers during de novo fibril formation but also binds to mature fibrils (Fig 2A). Because $\alpha$-synuclein fibrils that are formed in the presence of polyP (i.e., $\alpha$-syn ${ }^{\text {polyP }}$ ) have significantly altered morphology compared with fibrils formed in the absence of nucleators (i.e., $\alpha$-syn ${ }^{\text {alone}}$ ) (Cremers et al, 2016), we wondered whether polyP binding would also affect the morphology of mature fibrils. This would possibly explain why the addition of polyP to preformed fibrils was as cytoprotective as its addition during fibril formation (Cremers et al, 2016). We, therefore, generated $\alpha$-synuclein fibrils, washed and purified them to remove any small oligomers and protofibrils, and either left them untreated $\left(\alpha-\right.$ syn $\left.^{\text {alone}}\right)$ or incubated them with polyP $_{300}\left(\alpha\right.$-syn $\left.{ }^{\text {alone } \rightarrow \text { polyP }}\right)$. Immediately before as well as $20 \mathrm{~min}$ after the addition of polyP to $\alpha$-syn ${ }^{\text {alone }}$ fibrils, we fixed aliquots of the samples on grids and prepared them for transmission electron microscopy (TEM). As a control, we also tested $\alpha$-synuclein fibrils formed in the presence of polyP ( $\alpha$-syn $\left.{ }^{\text {polyp }}\right)$. As shown in Fig 2B (Fig S1), the morphology of $\alpha$-syn alone $\rightarrow$ polyp fibrils was nearly indistinguishable from the morphology of $\alpha$-syn ${ }^{\text {polyp }}$ fibrils. Instead of two protofilaments, which typically form a twisted structure, $\alpha$-syn ${ }^{\text {alone } \rightarrow \text { polyP }}$ and $\alpha$-syn ${ }^{\text {polyP }}$ fibrils were significantly thinner, suggesting that polyP caused their dissociation into single protofilaments. X-ray fibril diffraction measurements agreed with the finding that incubation of preformed fibrils with polyP alters their conformations and showed particularly striking differences in the equatorial plots of the radial intensities (i.e., $X$-axis), which arise from the packing of adjacent $\beta$-sheets in the amyloid fibril. In contrast, no differences were observed on the meridian ( $Y$-axis), which reflects the strand-to-strand packing, and produced a sharp reflection at $4.7 \AA$ spacing for both fibril species (Fig 2C and D). These results suggested a pronounced effect of polyP on the packing of the $\beta$-sheets within the protofilament (Fig 2E).

To further investigate the dynamics of polyP-fibril interactions, we conducted FP competition experiments with preformed $\alpha$-synpolyP $\mathrm{P}_{300-A F 647}$ fibrils (Fig 2F). As expected, we observed a high initial FP signal, consistent with the slow tumbling rate of polyP-fibril complexes. Upon addition of unlabeled poly $\mathrm{P}_{300}$, however, the FP signal rapidly decreased, indicating that the unlabeled polyP chains replaced the labeled polyP in the fibrils. Addition of the much shorter polyP $_{14}$ chain also reduced the FP signal but to a lesser extent, suggesting that shorter chains have lower binding affinities than longer chains (Fig 2F). These results indicated that the polyP-fibril interactions are highly dynamic in nature and implied that fibrils, 

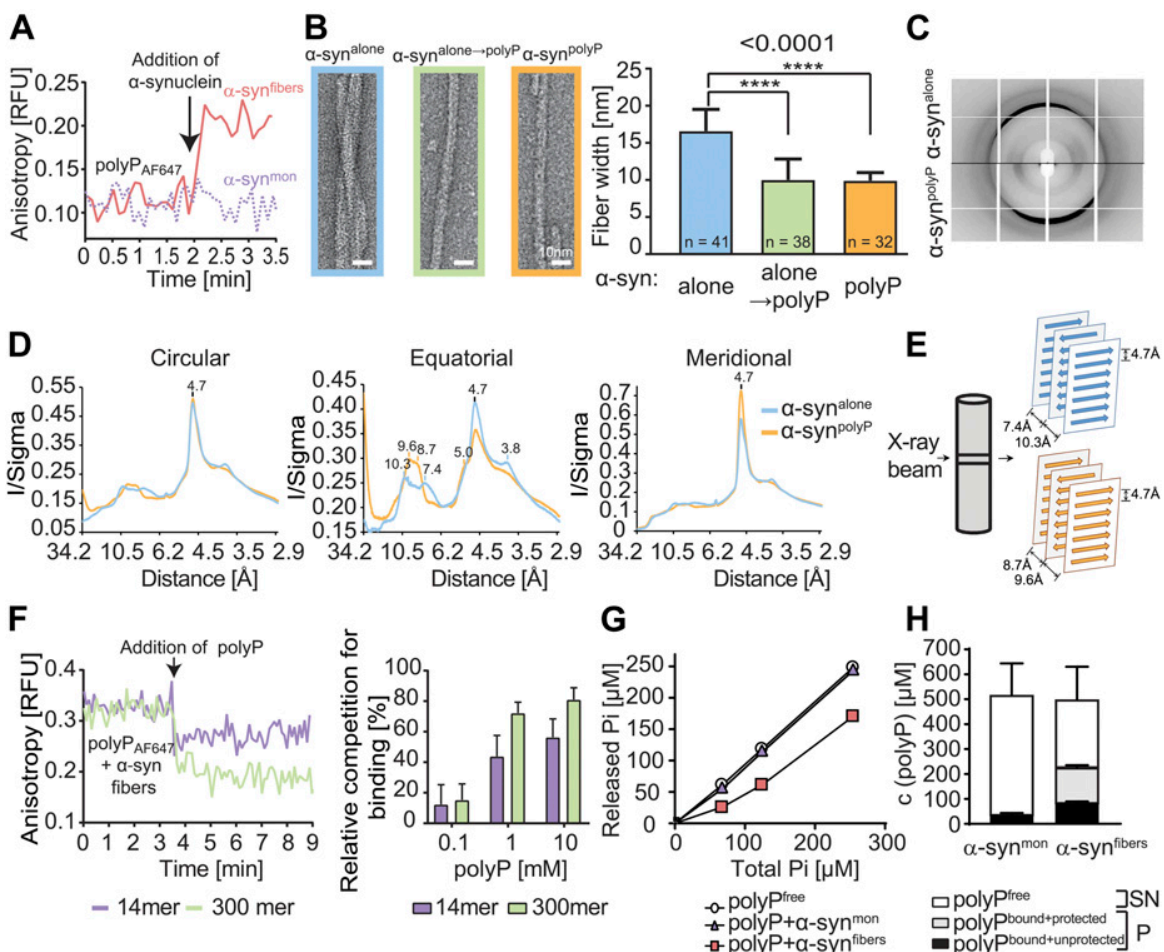

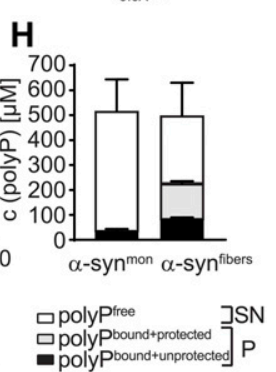

Figure 2. Effects of polyP on $\alpha$-synuclein fibril morphology.

(A) FP of $50 \mu \mathrm{M}$ polyP $\mathrm{P}_{300-A F 647}$ upon addition of $30 \mu \mathrm{M}$ $\alpha$-syn ${ }^{\text {mon }}$ or $\alpha$-syn ${ }^{\text {fibrils. The arrow indicates the time }}$ point of protein addition. (B) TEM of $\alpha$-synuclein fibrils $(300 \mu \mathrm{M})$ formed in the absence of polyP and left untreated ( $\alpha$-syn ${ }^{\text {alone }}$ ) or incubated with $7.5 \mathrm{mM}$ poly $\mathrm{P}_{300}$ for 20 min at RT ( $\alpha$-syn ${ }^{\text {alone } \rightarrow \text { polyP }}$ ). $\alpha$-synuclein fibrils formed in the presence of $7.5 \mathrm{mM}$ poly $\mathrm{P}_{300}$ were used as control $\left(\alpha-\right.$ syn $\left.^{\text {polyP }}\right)$. Quantitative analysis of fibril width was based on 10 individual micrographs and 32-41 $\alpha$-synuclein filaments per condition (additional images of representative fibers can be found in Fig S1). Statistical analysis was prepared with One-way ANOVA (****P-value $<0.0001)$. (C, D) X-ray fiber diffraction of $\alpha$-synuclein formed in the absence or presence of poly $P_{300}$. The oriented samples produced cross- $\beta$ diffraction patterns that contained a sharp reflection at $4.7 \AA$ spacing at the meridian ( $Y$-axis) and a broad reflection of $\sim 9 \AA$ spacing at the equator (X-axis) (C) The intensities were radially averaged over a full circle $\left(360^{\circ}\right.$, left panel), an equatorial arc $\left( \pm 30^{\circ}\right.$ around $\mathrm{X}$-axis, middle panel), and meridional arc $\left( \pm 30^{\circ}\right.$ around $Y$-axis, right panel) (D). (E) Cartoon representation of the possible ways $\beta$-sheets and strands assemble in the fibril. (F) Left panel: FP of 30 $\mu \mathrm{M}$ of preformed $\alpha$-synuclein-polyP $\mathrm{P}_{300-A F 647}$ fibrils before and after the addition of $1 \mathrm{mM}$ unlabeled poly $\mathrm{P}_{300}$ or poly $\mathrm{P}_{14}$. The arrow indicated the time point of polyP addition. Right panel: varying concentrations of poly $\mathrm{P}_{14}$ or poly $\mathrm{P}_{300}$ in the competition experiment. The percent competition was calculated

from the relative signal change upon polyP addition, setting the poly $\mathrm{P}_{300-\mathrm{AF} 647}$ fibril signal to $0 \%$ competition and the polyP $\mathrm{P}_{300-\mathrm{AF} 647}$ alone signal as $100 \%$ competition. The mean of three experiments $\pm S D$ is shown. (G) $40 \mu \mathrm{M} \alpha$-synuclein monomers (triangles) or preformed fibrils (squares) were incubated with increasing concentrations of poly $\mathrm{P}_{300}$ for $10 \mathrm{~min}$. The samples were treated with ScPPX and assayed for released $\mathrm{P}_{\mathrm{i}}$. A standard curve of poly $\mathrm{P}_{300}$ in the absence of $\alpha$-synuclein (circles) was used as control. (H) $40 \mu \mathrm{M} \alpha$-synuclein monomers or preformed fibrils were incubated with $500 \mu \mathrm{M}$ polyP 300 for $10 \mathrm{~min}$. The samples were separated into supernatant (SN) and pellet $(\mathrm{P})$, treated with ScPPX, and subsequently assayed for $\mathrm{P}_{\mathrm{i}}$. Poly $\mathrm{P}_{\text {bound-unprotected }}$ represents the amount of $\mathrm{P}_{\mathrm{i}}$ that was released upon ScPPX treatment in the pellet fraction. The amount of polyP not released by ScPPX was considered to be protected by the fibrils against hydrolysis (polyP $\mathrm{P}_{\text {bound }}+$ protected).

Source data are available for this figure.

even when formed in the absence of polyP, can rapidly adopt a novel conformation when exposed to polyP.

\section{PolyP-fibril complexes are polyphosphatase resistant}

Unbound polyP is very rapidly degraded by exopolyphosphatases, such as yeast polyphosphatase (PPX), which hydrolyzes the phosphoanhydride bonds with a turnover rate of $500 \mu \mathrm{mol} / \mathrm{mg} /$ min at $37^{\circ} \mathrm{C}$ (Wurst \& Kornberg, 1994). To test whether degradation of polyP reverses the morphological changes that we observed in fibrils bound to polyP, we incubated $\alpha$-syn ${ }^{\text {polyP }}$ fibrils with yeast PPX. Surprisingly, however, we did not observe any morphological changes in the $\alpha$-synuclein fibrils by TEM (data not shown). These results suggested either that the fibrils maintain their altered conformation even upon hydrolysis of polyP or that polyP, once in complex with fibrils, resists PPX-mediated hydrolysis. To investigate whether PPX is able to degrade fibril-associated polyP, we incubated $40 \mu \mathrm{M} \alpha$-synuclein monomers or preformed $\alpha$-synuclein fibrils with increasing concentrations of polyP, added PPX, and measured PPX-mediated release of $\mathrm{P}_{\mathrm{i}}$ using a modified molybdate assay (Christ \& Blank, 2018). Whereas polyP that was incubated with $\alpha$-synuclein monomers was rapidly hydrolyzed and yielded in the expected amount of $\mathrm{P}_{\mathrm{i}}$ (Fig $2 \mathrm{G}$, triangles), presence of $40 \mu \mathrm{M}$ $\alpha$-synuclein fibrils protected about $130 \mu \mathrm{M}$ of $\mathrm{P}_{\mathrm{i}}$ units against hydrolysis
(Fig 2G). We obtained very similar results when we incubated $40 \mu \mathrm{M}$ $\alpha$-synuclein monomers or fibrils with $500 \mu \mathrm{M}$ polyP, spun down polyPassociated fibrils and measured hydrolyzable polyP in both supernatant and pellet. More than 95\% of PPX-hydrolyzable polyP was found in the $\mathrm{SN}$ of samples containing soluble $\alpha$-synuclein monomers. In contrast, about $45 \%$ of the total polyP pelleted with $\alpha$-synuclein fibrils, of which about two-thirds $(\sim 130 \mu \mathrm{M})$ were resistant towards PPX-mediated hydrolysis (Fig $2 \mathrm{H}$ ). We concluded from these results that polyP- $\alpha$-synuclein-fibrils are apparently stable and resistant towards exopolyphosphatase-mediated polyP hydrolysis.

\section{Extracellular polyP prevents intracellular enrichment of $\alpha$-synuclein fibrils}

Our findings that polyP associates with preformed $\alpha$-synuclein fibrils and changes their conformation served to explain results of our previous studies, which showed that $\alpha$-synuclein fibrils lose their cytotoxicity as soon as polyP is added (Cremers et al, 2016). However, they did not explain how polyP is able to protect against amyloid toxicity. We reasoned that polyP might reduce the formation of cytotoxic oligomers by stabilizing the fibrils in a conformation that has previously been shown to be less prone to shedding (Cremers et al, 2016). Alternatively, we considered that binding of polyP to the fibrils might either directly or indirectly 
interfere with the membrane association of $\alpha$-synuclein (van Rooijen et al, 2008; Grey et al, 2011) and / or its cellular uptake (Reyes et al, 2015; Karpowicz et al, 2017). Last, it was also conceivable that polyP binding might increase the turnover of internalized $\alpha$-synuclein or its sequestration into nontoxic deposits.

To gain insights into the potential mechanism(s) by which polyP protects neuronal cells against amyloid toxicity, we compared uptake and intracellular fate of exogenously added $\alpha$-synuclein fibrils in the absence and presence of polyp. We labeled $\alpha$ synuclein with Alexa Fluor 488, formed mature fibrils, pelleted them by centrifugation, and sonicated the fibrils to obtain a mixture of oligomeric species, protofibrils, and short mature fibrils (i.e., $\alpha$ -

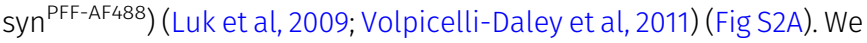
confirmed that sonication does not affect the interaction of fibrils with polyP (Fig S2B). We then incubated differentiated SH-SY5Y neuroblastoma cells with $\alpha$-Syn ${ }^{\text {PFF-AF488 }}$ or freshly prepared fluorescently labeled monomeric $\alpha$-synuclein (i.e., $\alpha$-syn ${ }^{\text {mon-AF488 }}$ ) at either $4^{\circ} \mathrm{C}$ or $37^{\circ} \mathrm{C}$ in the absence or presence of polyP for $24 \mathrm{~h}$ and analyzed AF488 fluorescence using confocal microscopy. In the absence of polyP, we detected significant intracellular fluorescence upon incubation of the cells with either $\alpha$-Syn ${ }^{\text {mon-AF488 }}$ or $\alpha$-Syn ${ }^{\text {PFF-AF488 }}$ at $37^{\circ} \mathrm{C}$ but not at $4^{\circ} \mathrm{C}$ (Fig $3 \mathrm{~A}$ ). Moreover, we noted an apparently stable association of $\alpha$-syn ${ }^{\text {PFF-AF488 }}$ with the cell membrane at both temperatures (Fig 3A), which was confirmed by trypan blue staining (Fig S4A). These results were fully consistent with previous studies, which reported that both monomers and fibrils use a temperaturesensitive endocytic route for their cellular uptake (Rodriguez et al, 2018) and that $\alpha$-synuclein fibrils stably associate with cell membranes (Karpowicz et al, 2017). Incubation of the cells in the presence of polyP at concentrations ranging from 10 to $500 \mu \mathrm{M}$ increasingly reduced the intracellular fluorescence signal of $\alpha$-Syn ${ }^{\text {PFF-AF488 }}$ upon incubation at $37^{\circ} \mathrm{C}$ as well as the membrane-associated signal upon incubation at either temperature (Figs $3 \mathrm{~A}$ and S3). This result was

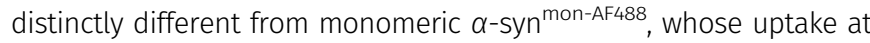
$37^{\circ} \mathrm{C}$ was not affected by polyP. These results strongly suggested that polyP negatively influences the membrane association and/or uptake of $\alpha$-Syn ${ }^{\text {PFF-AF488. }}$.

To test whether intracellular polyP influenced the uptake and/or intracellular foci formation of exogenously added $\alpha$-syn ${ }^{\text {PFF-AF488, we }}$ incubated differentiated SH-SY5Y neuroblastoma cells with fluorescently labeled poly $\mathrm{P}_{300}$ (i.e., poly $\mathrm{P}_{300-A F 647}$ ) for $24 \mathrm{~h}$, washed the cells to remove any exogenous polyP, and analyzed the cells using a confocal microscope. We observed a clear AF647 fluorescence signal in cells incubated with fluorescently labeled
A
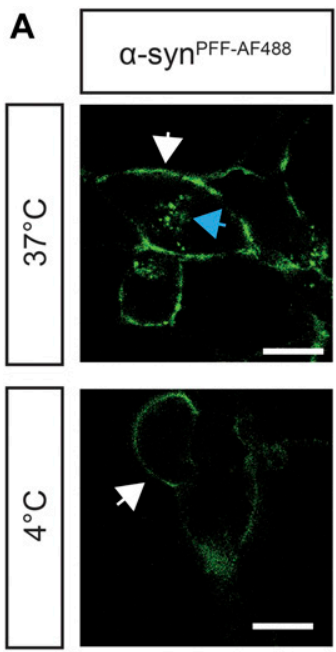

B
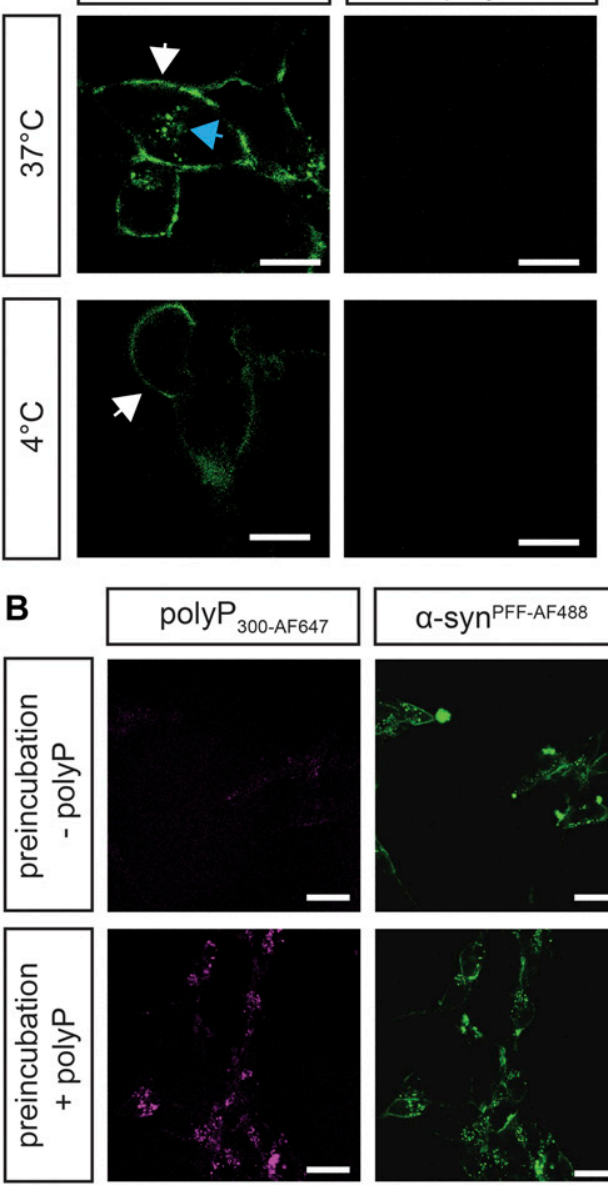
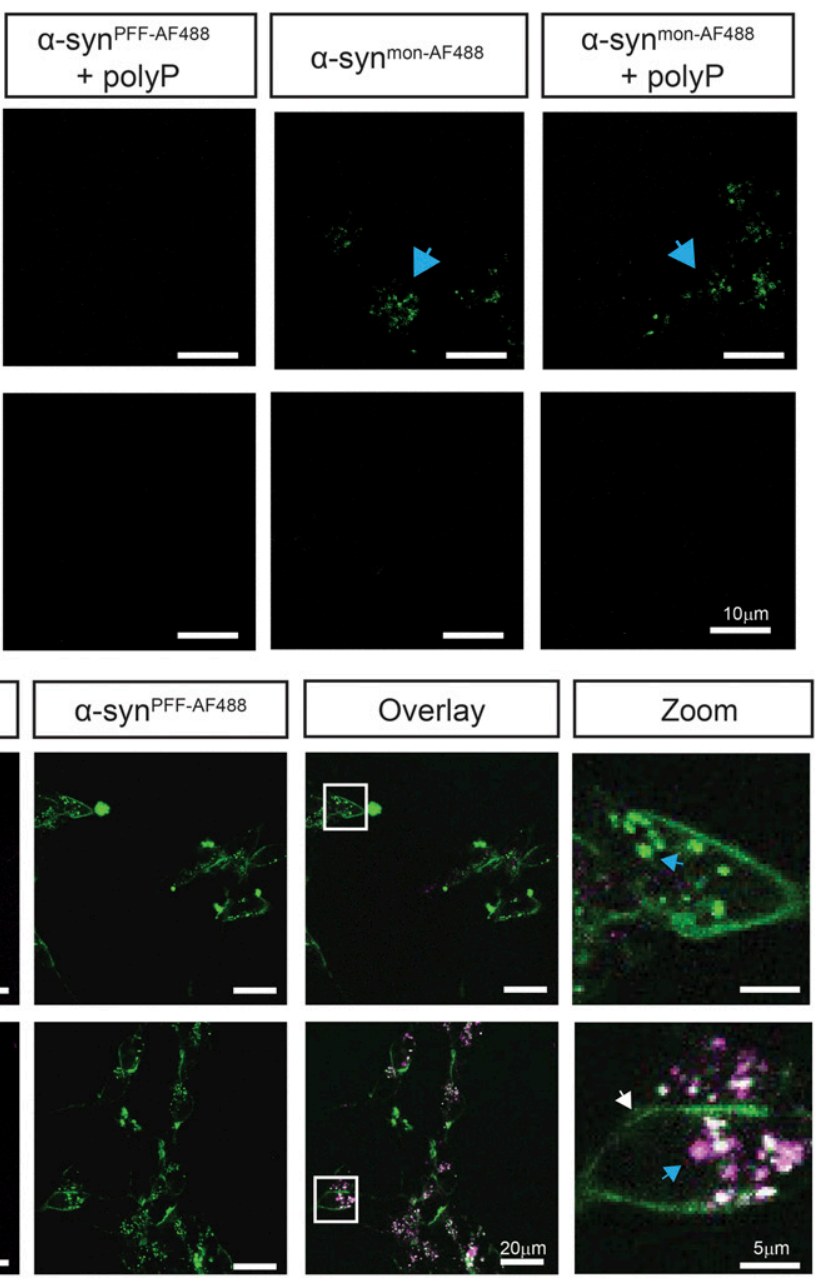

Figure 3. Extracellular polyP prevents intracellular enrichment of $\alpha$-synuclein fibrils.

(A) Differentiated SH-SY5Y neuroblastoma cells were incubated with $3 \mu \mathrm{M}$ freshly purified monomeric $\alpha$-syn ${ }^{\text {mon-AF488 }}$ or $\alpha$-syn ${ }^{\text {PFF-AF488 }}$ fibrils in the absence or presence of $250 \mu \mathrm{M}$ poly $\mathrm{P}_{300}$ (in $\mathrm{P}_{\mathrm{i}}$-units) at either $4^{\circ} \mathrm{C}$ or $37^{\circ} \mathrm{C}$ for $3 \mathrm{~h}$. Membrane-associated $\alpha-\operatorname{syn}^{\mathrm{AF} 488}$ is indicated with white arrows, whereas internalized $\alpha-$ syn $^{\text {AF488 }}$ is indicated with blue arrows. Brightness and contrast adjustments have been equally applied to all images. (B) Intracellular enrichment of cells with poly $\mathrm{P}_{300}$ neither affects uptake nor turnover of

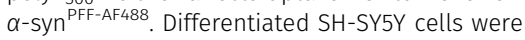
incubated with $250 \mu \mathrm{M}$ poly $\mathrm{P}_{300-A F 647}$ at $37^{\circ} \mathrm{C}$ for $24 \mathrm{~h}$ and washed to remove extracellular polyP. Then, $3 \mu \mathrm{M}$ preformed $\alpha$-syn ${ }^{\text {PFF-AF488 }}$ fibrils were added and fluorescence microscopy was conducted after $24 \mathrm{~h}$ of incubation. Brightness and contrast adjustments have been equally applied to all images. 
polyP but not in our control cells (Fig S4B). This result confirmed previous studies that showed neuronal cells are able to take up and enrich exogenous polyP (Fig S4B) (Holmstrom et al, 2013). When we incubated the polyP-enriched cells with $\alpha$-Syn ${ }^{\text {PFF-AF488, }}$ we observed the same rapid internalization and intracellular enrichment of $\alpha$-Syn ${ }^{\text {PFF-AF488 }}$ fibrils that we found in cells that were not pretreated with polyP (Fig 3B). We concluded from these experiments that polyP needs to be present in the extracellular space to interfere with the uptake of $\alpha$-Syn ${ }^{\mathrm{PFF}}$, and that intracellular polyP does not substantially affect the fate of internalized $\alpha$-synuclein fibrils. This is despite the fact that we observed a clear colocalization between internalized $\alpha$-syn ${ }^{\text {PFF-AF488 }}$ and intracellular poly $\mathrm{P}_{300-\mathrm{AF} 647}$ in select intracellular foci, demonstrating that polyP associates with $\alpha$-syn ${ }^{\text {PFF-AF488 }}$ also in the context of intact cells (Fig 3B, blue arrow).

\section{PolyP interferes with $\alpha$-syn ${ }^{\text {PFF }}$ membrane association}

To further investigate the influence of polyP on fibril uptake, we incubated differentiated SH-SY5Y cells with $\alpha$-Syn ${ }^{\text {PFF-AF488 }}$ as before, and either left them untreated or added polyP-defined time points after start of the incubation. We reasoned that determining the effects of polyp on cells that contained both membrane-associated and internalized $\alpha$-Syn ${ }^{\text {PFF-AF488 }}$ would likely reveal at what stage polyP acts. Before the imaging, we washed the cells to remove any unbound $\alpha$-Syn ${ }^{\text {PFF }}$ and/or polyP. As expected, incubation of SH-SY5Y neuroblastoma cells with $\alpha$-Syn ${ }^{\text {PFF-AF488 }}$ in the absence of polyP revealed a persistent association of labeled $\alpha$-Syn ${ }^{\text {PFF-AF488 }}$ with the cell membrane, and a steady increase in the intracellular fluorescent signal (Fig 4A). When we added polyP to cells that were preincubated with $\alpha$-syn ${ }^{\text {PFF-AF488 }}$ for $2 \mathrm{~h}$ and imaged the samples 30 min later, we observed a significantly reduced signal of membrane-associated $\alpha$-Syn ${ }^{\text {PFF-AF488 }}$ and lower levels of intracellular $\alpha$-Syn ${ }^{\text {PFF-AF488 }}$ compared with the control cells. In the presence of polyP, the fluorescence signals did not significantly change over the next hours of incubation and only a slight increase in the intracellular signal of $\alpha$-Syn ${ }^{\text {PFF-AF488 }}$ was observed after $24 \mathrm{~h}$ of incubation. Addition of polyP at later time points (i.e., 4 or $6 \mathrm{~h}$ ) caused a similar cessation in $\alpha$-Syn ${ }^{\text {PFF-AF488 }}$ uptake and a decrease in cell membrane-associated $\alpha$-Syn ${ }^{\text {PFF-AF488 }}$ signal (Fig 4A). Upon addition of fluorescently labeled poly $\mathrm{P}_{300-A F 647}$ to cells pretreated with $\alpha$-Syn ${ }^{\text {PFF-AF488 }}$ for 6 h, we found both fluorescence signals to co-localize on the outside of the cells, consistent with the formation of polyP-fibril complexes (Fig 4B). These results strongly suggested that binding of polyP to $\alpha$-synuclein fibrils interferes with the membrane association of $\alpha$-synuclein and, hence, prevents the uptake of fibrils. They also served to explain why the uptake of monomeric $\alpha$-synuclein, which does not stably interact with polyP, is unaffected by the presence of polyP.

Recent studies suggested that one mechanism by which $\alpha$ $\mathrm{syn}^{\text {PFF-AF488 }}$ enter cells is through the interaction with heparin glycan receptors (Ihse et al, 2017), in a mechanism termed micropinocytosis (Nakase et al, 2004). To investigate the possibility that polyP inhibits the uptake of $\alpha$-syn ${ }^{\text {PFF-AF488 }}$ by generally blocking micropinocytosis, we monitored the influence of polyP on the uptake of the trans-activator of transcription (TAT) protein fused to the fluorescent dye TAMRA (TATTAMRA) (AnaSpec). TAT is a small viral protein, which contains the heparan sulfate-binding sequence necessary for its internalization via micropinocytosis (Wadia et al, 2004; Kaplan et al, 2005). We incubated differentiated SH-SY5Y cells with both TAT-5-(and-6)Carboxytetramethylrhodamine, Succinimidyl Ester (TAMRA) and $\alpha-$ Syn $^{\text {PFF-AF488 }}$ either in the absence or in the presence of polyP $\mathrm{P}_{300}$ and monitored the uptake of both proteins via fluorescence microscopy. In the absence of polyP ${ }_{300}$, we observed signals for both $\alpha$-Syn ${ }^{\text {PFF-AF488 }}$ and TAT-TAMRA in the cells, indicating that both proteins were taken up (Fig 4C). In the presence of polyP, however, we observed only the TATTAMRA signal inside the cells (Fig 4C). These results are consistent with the model that polyP selectively prevents the uptake of fibrillary $\alpha$ synuclein without generally interfering with endocytosis mechanisms.

To finally test whether the chain lengths of polyP influences its

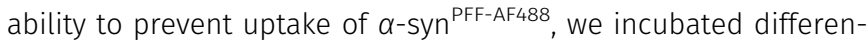
tiated SH-SY5Y cells with $\alpha$-Syn ${ }^{\text {PFF-AF488 }}$ as before but added $250 \mu \mathrm{M}$ (in $\mathrm{P}_{\mathrm{i}}$-units) of either poly $\mathrm{P}_{14}$, poly $\mathrm{P}_{130}$, or poly $\mathrm{P}_{300}$. Analysis of internalized $\alpha$-syn ${ }^{\text {PFF-AF488 }}$ after $24 \mathrm{~h}$ demonstrated that whereas the longer polyP chains completely inhibited the uptake of $\alpha$-syn ${ }^{\text {PFF-AF488, }}$, presence of poly $\mathrm{P}_{14}$ had a much diminished effect on the uptake (Fig 4D). These results were in excellent agreement with our previous competition studies that showed poly $\mathrm{P}_{14}$ chains are substantially less effective in binding to $\alpha$-Syn PFF-AF488 $^{\text {and/or }}$ competing with poly $\mathrm{P}_{300}$ and excluded that the observed effects are simply due to the presence of densely charged polyanions. Instead, these results provided supportive evidence for the conclusion that the mechanism by which polyP protects neuronal cells against $\alpha$ synuclein toxicity is through its specific interactions with extracellular $\alpha$-synuclein fibrils, effectively preventing their association with the cell membrane and limiting their uptake into neuronal cells.

\section{Discussion}

\section{Effects of polyP on $\alpha$-synuclein fibril formation and structure}

Previous work from our laboratory demonstrated that polyP effectively accelerates fibril formation of disease-related amyloids and protects against amyloid toxicity both in cell culture as well as in disease models of Caenorhabditis elegans (Cremers et al, 2016). To gain insights into the mechanism by which polyP exerts these effects, we tested at what stage during the fibril-forming process, polyP acts on $\alpha$-synuclein, one of the major amyloidogenic proteins involved in PD. These studies showed that polyP is unable to accelerate the rate-limiting step of $\alpha$-synuclein fibril formation. Instead, polyP binds to $\alpha$-synuclein species that begin to accumulate at the end of the lag phase and are present throughout the elongation and stationary phase of fibril formation. These results agreed well with previous solution studies, which showed that polyP does not promote the conversion of $\alpha-$ helical proteins into $\beta$-sheet structures but instead stabilizes folding intermediates once they have adopted a $\beta$-sheet conformation (Yoo et al, 2018). These results also make physiological sense as they exclude the possibility that simple co-presence of polyP and $\alpha$-synuclein in the same cellular compartment cause fibril formation.

Earlier work on $\alpha$-synuclein has shown that the primary nucleation step involves structural changes within $\alpha$-synuclein monomers and formation of small pre-fibrillar oligomeric intermediates, which are rich in $\beta$-sheet structures yet unable to 


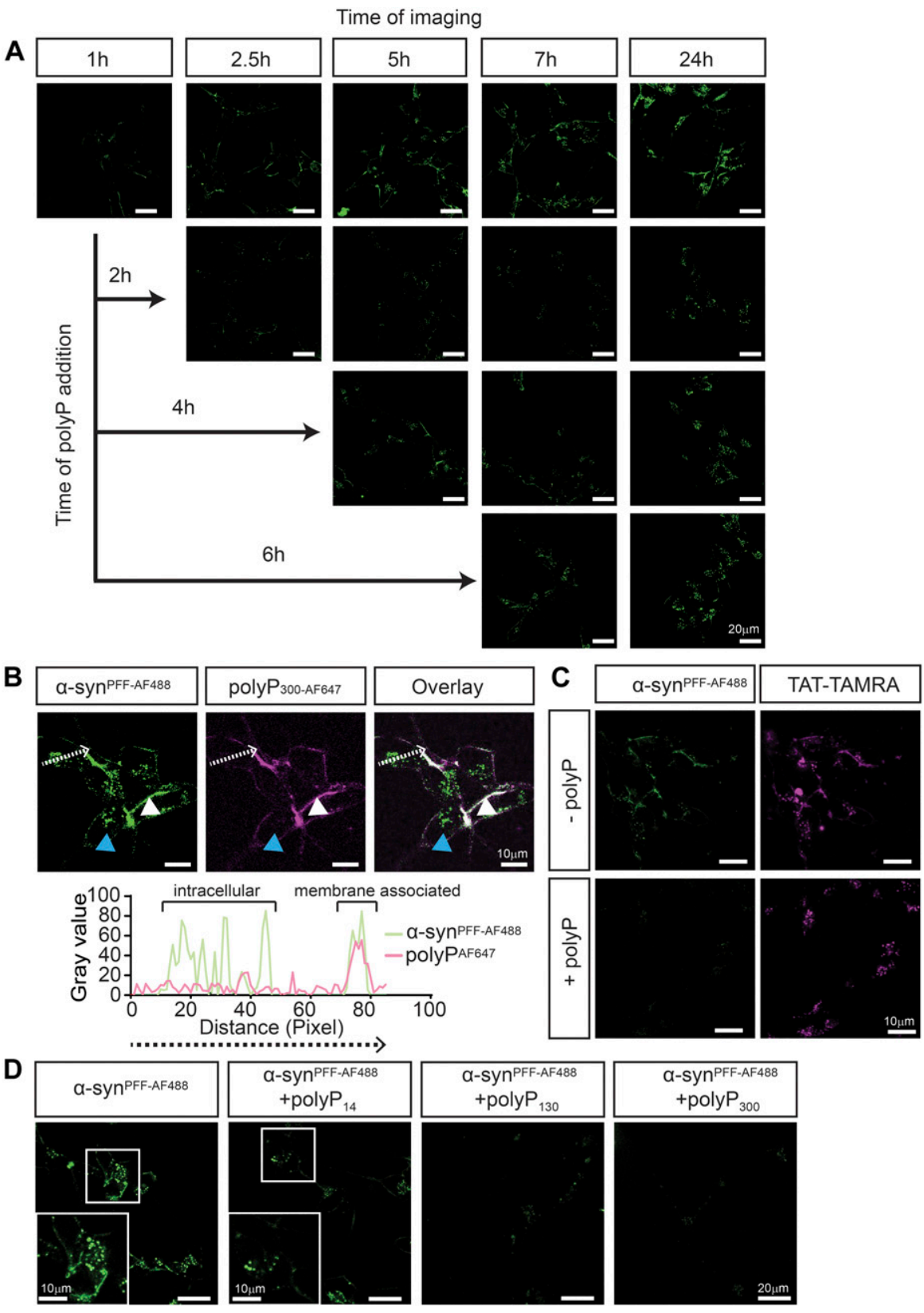

Figure 4. PolyP prevents the association of $\alpha$-synuclein fibrils with the membrane.

(A) Uptake of $3 \mu \mathrm{M}$ preformed $\alpha$-Syn ${ }^{\text {PFF-AF488 }}$ fibrils after 1, 2.5, 5, 7 and $24 \mathrm{~h}$ into differentiated SH-SY5Y cells. After 2, 4, or $6 \mathrm{~h}$ of incubation, $250 \mu \mathrm{M}$ polyP 300 -AF647 was added, and the uptake of $\alpha$-syn ${ }^{\text {PFF-AF488 }}$ fibrils was monitored as indicated. Brightness and contrast adjustments have been equally applied to all images. (B) Upper panel: differentiated SH-SY5Y cells were incubated with $3 \mu \mathrm{M}$ preformed $\alpha$-Syn ${ }^{\text {PFF-AF488 }}$ fibrils for $6 \mathrm{~h}$. Then, $250 \mu \mathrm{M}$ poly $\mathrm{P}_{300-A F 647}$ was added and co-localization of $\alpha$-Syn ${ }^{\text {PFF-AF488 }}$ fibrils and poly $\mathrm{P}_{300-A 5647}$ was determined. The intracellular $\alpha$-syn ${ }^{\mathrm{PFF}-\mathrm{AF} 467}$ signal is indicated with blue arrows, whereas extracellular $\alpha$-Syn ${ }^{\text {PFF-AF } 467}$ is indicated with white arrows. polyP $\mathrm{P}_{300-\mathrm{AF} 647}$ was only detected on the cell surface. Lower panel: fluorescence signal of $\alpha$-syn ${ }^{\text {PFF-AF488 }}$ fibrils and polyP $300-A F 647$ as measured along the white line marked in the upper figure using the plot profile analysis in Imagej. (c) Brightness and contrast have been adjusted to for ideal comparison $\alpha$-Syn ${ }^{\text {PFF-AF467 }}$ and polyP ${ }_{300-A F 647}$ signal. (C) Differentiated SH-SY5Y cells were incubated with $5 \mu \mathrm{M}$ TAT-TAMRA and $3 \mu \mathrm{M} \alpha$-Syn ${ }^{\mathrm{PFF}-A F 488}$ in the presence or absence of $250 \mu \mathrm{M}$ poly $\mathrm{P}_{300}$. After $3 \mathrm{~h}$ of incubation, the uptake was monitored. Brightness and contrast adjustments have been equally applied to all images. (D) Differentiated SH-SY5Y cells were incubated with $\alpha$-synuclein fibrils for $24 \mathrm{~h}$ in the absence or presence of $250 \mu \mathrm{M}$ of different chain lengths of polyP. Brightness and contrast adjustments have been equally applied to all images.

increase ThT-fluorescence (Conway et al, 2000a; Krishnan et al, 2003; Mehra et al, 2018). It has been proposed that these oligomers undergo a cooperative conformational change, leading to the formation of ThT-positive protofibrils and fibrils (Mehra et al, 2018). Our findings that polyP binding slightly, yet reproducibly, precedes ThT binding and substantially accelerates the formation of ThTpositive protofibrils and fibrils suggest that polyP serves as a binding scaffold for pre-fibrillar oligomers and increases the cooperativity of fibril formation.

A recently solved cryo-EM structure of mature $\alpha$-synuclein s-121 $_{12}$ fibrils revealed that the double-twisted nature of the fibrils results from the association of two protofilaments, which are stabilized by intermolecular salt bridges (Fig S5) (Guerrero-Ferreira et al, 2018).
Moreover, the fibrils are characterized by dense positively charged patches that are located in the vicinity of the interface and run in parallel to the fibril axis. We now hypothesize that binding of the negatively charged polyP chains to such densely positively charged patches that run alongside individual oligomers will support the correct orientation of the oligomers along the fiber axis, hence, nucleate fibril formation. This model would explain why polyP shows very low apparent affinity for soluble $\alpha$-synuclein monomers and provide some rationale for the very low binding stoichiometry of polyP to $\alpha$-synuclein, which is a mere $5 \mathrm{P}_{\mathrm{i}}$-units per one $\alpha$ synuclein monomer. However, future high-resolution structure studies are clearly necessary to answer the important question as to how polyP and $\alpha$-synuclein fibrils interact. 
Our studies showed that polyp does not only change the morphology of $\alpha$-synuclein fibrils when present during de novo fibril formation but also of mature $\alpha$-synuclein fibrils. These results agree with recent findings, which suggested that fibrils are intrinsically dynamic and can adopt different conformations over a time scale of weeks to months (Sidhu et al, 2017). Given that the two strands associate via charge-charge interactions (Fig S5), the most obvious explanation is that the negatively charged polyP causes repulsion of the two strands, thereby initiating dissociation. It will be interesting to assess the relative effects of polyP on the fibril morphology of disease-associated mutant, which appears to be more resistant to morphology changes than wild-type $\alpha$-synuclein. In either case, however, our results suggest that polyP might play a pivotal role as modifier of disease-associated fibrils.

\section{Mechanistic insights into polyP's protective role against $\alpha$-synuclein toxicity}

The toxicity associated with $\alpha$-synuclein fibril formation has long been attributed to the cellular accumulation of insoluble fibril deposits (El-Agnaf \& Irvine, 2000; Goldberg \& Lansbury, 2000). However, increasing evidence now suggests that oligomeric intermediates, which accumulate during amyloid fibril formation, interfere with membrane integrity, mitochondrial activity, and/or other physiologically important functions and elicit the neuroinflammatory responses associated with the disease (Chen et al, 2015). Similarly, disease progression has also been proposed to be the responsibility of amyloid oligomers, which appear to be able to spread from cell to cell in a prion-like manner (Li et al, 2008; Danzer et al, 2009; Desplats et al, 2009). Rodents that were subjected to $\alpha$-syn ${ }^{\text {PFF }}$ injections into the striatum, for instance, developed neurodegeneration in the substantia nigra (Luk et al, 2012; Paumier et al, 2015). These results suggested that physiologically relevant amyloid modifiers, such as polyP, which are present in the extracellular space in the brain (Holmstrom et al, 2013) and protect against amyloid-induced cytotoxicity in cell culture models, might be involved in the spreading of the disease. We now revealed that binding of polyP to extracellular $\alpha$-syn ${ }^{\text {PFF }}$ decreased the membrane association of $\alpha-$ syn $^{\mathrm{PFF}}$ and significantly reduced the internalization of $\alpha$-synuclein fibrils (Fig 5), likely explaining the reason for polyP's cytoprotective effects. We found this effect to be highly specific for amyloid fibrils because neither the uptake of $\alpha$-synuclein monomers nor of TAT-TAMRA, which, like $\alpha$-syn ${ }^{\text {PFF }}$ is internalized via micropinocytosis (Wadia et al, 2004; Kaplan et al, 2005), was affected by the presence of polyP. Moreover, shorter polyP chain lengths, which are much less effective in interacting with $\alpha$-syn ${ }^{\text {PFF }}$ compared with longer chains, were found to be also much less effective in preventing the uptake of the fibrils. Finally, we found that intracellular enrichment with polyP had no effect on the amount of internalized $\alpha$-synuclein fibrils, indicating that polyP blocks the uptake and not the intracellular turnover rate of $\alpha$-syn ${ }^{\text {PFF. }}$. These results suggested that the direct interaction between polyP and $\alpha-$ syn $^{\text {PFF }}$, through alterations in fibril conformations and/or the abundance of negative charges associated with $\alpha$-syn ${ }^{\text {PFF }}$, prevents the interactions of $\alpha$-syn ${ }^{\mathrm{PFF}}$ fibrils with the negatively charged lipids on the cell membrane and leads to its dissociation from the

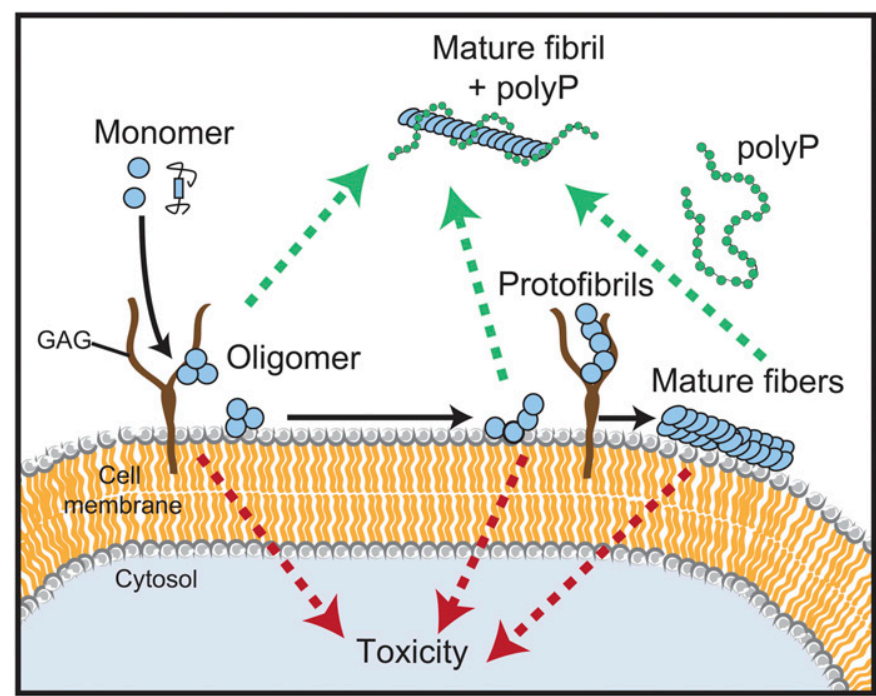

Figure 5. Model for the influence of polyP on fibril formation, morphology, and uptake.

PolyP accelerates amyloid fibril formation by nucleating pre-fibrillar oligomers. PolyP-associated fibrils have significantly altered fibril morphology. The interaction of polyP with amyloidogenic $\alpha$-synuclein interferes with their membrane association and there prevents cellular uptake.

membrane (Ihse et al, 2017). Given that the toxicity of $\alpha$-synuclein amyloids is attributed to their ability to bind, penetrate, and damage the membrane (van Rooijen et al, 2009; Reynolds et al, 2011), our finding that a physiologically relevant compound affects this process and suggests that polyP might play an important role in the development and/or progression of this disease. Tools need to be developed to quantify, monitor, and manipulate extra- and intracellular polyP levels and test the exciting idea that prevention of the reported age-associated polyP decline in mammalian brains (Lorenz et al, 1997) might serve to delay the onset and/or extent of this devastating disease.

\section{Materials and Methods}

\section{PolyP preparation}

Defined chain length polyP was a kind gift from Dr. Toshikazu Shiba (RegeneTiss). PolyP was labeled with Alexa Fluor 647 as described (Choi et al, 2010). In brief, $125 \mu \mathrm{M}$ of poly $\mathrm{P}_{300}$ chain was incubated with $2.5 \mathrm{mM}$ Alexa Fluor 647 cadaverine (Life Technologies) and 200 mM 1-ethyl-3- (3-dimethylaminopropyl) carbodiimide (EDAC) (Invitrogen) in water for $1 \mathrm{~h}$ at $60^{\circ} \mathrm{C}$. The reaction was stopped on ice and labeled polyP $\mathrm{P}_{300-\mathrm{AF} 647}$ was separated from free dye and unlabeled polyP via a NAP-5 column (GE Healthcare) that was equilibrated with $40 \mathrm{mM} \mathrm{KPi}$, pH 7.5. The concentration of polyP was determined via a toluidine blue assay (Mullan et al, 2002). In this assay, polyP was mixed with $6 \mathrm{mg} / \mathrm{l}$ toluidine blue and the absorbance was measured at 530 and $630 \mathrm{~nm}$. The 530/630 nm absorbance ratio was determined and the concentration was calculated based on a poly $\mathrm{P}_{300}$ standard curve. 


\section{Protein purification and labeling of $\alpha$-synuclein}

Alpha-synuclein WT or $\alpha$-synuclein A90C mutant was purified as described (Jain et al, 2013; Cremers et al, 2016) with slight modifications. In brief, Escherichia coli strain BL21 (DE3) containing the $\alpha$-synuclein-expressing vector pT7-7 was grown in Luria broth, supplemented with $200 \mu \mathrm{g} / \mathrm{ml}$ ampicillin until OD $_{600}$ of $0.8-1.0$ was reached. The protein expression was induced with $0.8 \mathrm{mM} \mathrm{IPTG} \mathrm{for} 4 \mathrm{~h}$. Then, bacteria were harvested at 4,500 $\mathrm{g}$ for $20 \mathrm{~min}$ and $4^{\circ} \mathrm{C}$. The pellet was resuspended in $50 \mathrm{ml}$ lysis buffer ( $10 \mathrm{mM}$ Tris- $\mathrm{HCl}$, pH 8.0, $1 \mathrm{mM}$ EDTA, Roche Complete protease inhibitor cocktail) and the lysate was boiled for 15-20 min. The aggregated proteins were removed by centrifugation at 13,500g for $30 \mathrm{~min}$. Next, $136 \mu \mathrm{l} / \mathrm{ml}$ of a $10 \% \mathrm{wt} / \mathrm{vol}$ solution streptomycin sulfate solution and $228 \mu \mathrm{l} / \mathrm{ml}$ glacial acetic acid were added to the supernatant. After another centrifugation step at 13,500 $\mathrm{g}$ for $30 \mathrm{~min}$, the supernatant was removed and mixed in a 1:1 ratio with saturated ammonium sulfate and incubated stirring at $4^{\circ} \mathrm{C}$ for $1 \mathrm{~h}$. The mixture was spun down at $13,500 \mathrm{~g}$ for $30 \mathrm{~min}$ and the pellet was resuspended in $10 \mathrm{mM}$ Tris- $\mathrm{HCl}, \mathrm{pH}$ 7.5. Concentrated $\mathrm{NaOH}$ was used to adjust the $\mathrm{pH}$ of the suspension to $\mathrm{pH}$ 7.5. Afterwards, the protein was dialyzed against $10 \mathrm{mM}$ Tris- $\mathrm{HCl}, \mathrm{pH} 7.5,50 \mathrm{mM} \mathrm{NaCl}$, filtered, and loaded onto three connected $5 \mathrm{ml} \mathrm{HiTrap} \mathrm{Q} \mathrm{HP} \mathrm{columns} \mathrm{(GE} \mathrm{Healthcare).}$ Washing steps were performed with $10 \mathrm{mM}$ Tris- $\mathrm{HCl}, \mathrm{pH}$ 7.5, $50 \mathrm{mM}$ $\mathrm{NaCl}$ and the protein was eluted with a linear gradient from 50 to $500 \mathrm{mM} \mathrm{NaCl}$. The protein-containing fractions were combined and dialyzed against $50 \mathrm{mM}$ ammonium bicarbonate, $\mathrm{pH}$ 7.8. Oligomeric $\alpha$-synuclein species were removed by filtering the protein through a 50-kD cutoff column (Amicon, Millipore). Aliquots of the protein were prepared, lyophilized, and stored at $-80^{\circ} \mathrm{C}$. For crosslinking of $\alpha$-synuclein-A90C with Alexa Fluor 488-maleimide (Invitrogen), 100 $\mu \mathrm{M}$ of the protein was incubated with $1 \mathrm{mM}$ Tris(2-carboxyethyl) phosphine (Invitrogen) for $30 \mathrm{~min}$ at RT protected from light. Alexa Fluor 488-maleimide was added in threefold excess and the mixture was incubated overnight at $4^{\circ} \mathrm{C}$. The reaction was stopped by adding $2 \mathrm{mM}$ dithiothreitol. The free dye was removed using an NAP column (GE Healthcare). The concentration of dye and protein were determined by measuring absorbance at 488 and $280 \mathrm{~nm}$, respectively. Saccharomyces cerevisiae exopolyphosphate (ScPPX) was purified according to Pokhrel et al (2019) with slight modifications. In brief, MJG317 (BL21/pScPPX2 = S. cerevisiae PPX1 in pET-15b) was incubated overnight at $37^{\circ} \mathrm{C}$ without shaking in LB containing $100 \mu \mathrm{g} \mathrm{mL}^{-1}$ ampicillin. The next day, the cultures were shaken for about $30 \mathrm{~min}$ at $180 \mathrm{rpm}$ at $37^{\circ} \mathrm{C}$ until they reach an absorbance of 0.4-0.5. Additional $100 \mu \mathrm{g} \mathrm{mL}^{-1}$ ampicillin and IPTG to a final concentration of $1 \mathrm{mM}$ were added and protein was expressed by incubating the cells for $4 \mathrm{~h}$ at $37^{\circ} \mathrm{C}$ with shaking at 180 $\mathrm{rpm}$. The cells were harvested by centrifuging for $20 \mathrm{~min}$ at 4,000 $\mathrm{rpm}$ at $4^{\circ} \mathrm{C}$. The pellet was resuspended in $50 \mathrm{mM}$ sodium phosphate buffer, $500 \mathrm{mM} \mathrm{NaCl}, 10 \mathrm{mM}$ imidazole $(\mathrm{pH}$ 8) and $1 \mathrm{mg} / \mathrm{mL}$ lysozyme, $2 \mathrm{mM} \mathrm{MgCl}$, and $50 \mathrm{U} / \mathrm{mL}$ Benzonase was added. The solution was incubated for $30 \mathrm{~min}$ on ice to digest nucleotides. Cell lyses was performed via sonication with two cycles of $50 \%$ power pulsing $5 \mathrm{~s}$ on and $5 \mathrm{~s}$ off for 2 min with 2 min rest between cycles. The protein lysate was centrifuged to remove cell debris for $20 \mathrm{~min}$ at $20,000 \mathrm{~g}$ at $4^{\circ} \mathrm{C}$ and loaded onto a nickel-charged chelating column. After washing with $50 \mathrm{mM}$ sodium phosphate buffer, $0.5 \mathrm{M}$
$\mathrm{NaCl}$ and $10 \mathrm{mM}$ imidazole ( $\mathrm{pH}$ 8), and $50 \mathrm{mM}$ sodium phosphate buffer, $0.5 \mathrm{M} \mathrm{NaCl}$ and $20 \mathrm{mM}$ imidazole ( $\mathrm{pH}$ 8), the samples were eluted with $50 \mathrm{mM}$ sodium phosphate buffer, $0.5 \mathrm{M} \mathrm{NaCl}$ and $0.5 \mathrm{M}$ imidazole $(\mathrm{pH} 8)$. Fractions containing ScPPX were pooled and dialyzed twice against 2 liters of $20 \mathrm{mM}$ Tris- $\mathrm{HCl}(\mathrm{pH} 7.5), 50 \mathrm{mM} \mathrm{KCl}$, $30 \%$ (vol/vol) glycerol. Precipitated protein was removed via centrifugation for $20 \mathrm{~min}$ at 20,000 $\mathrm{g}$ at $4^{\circ} \mathrm{C}, 50 \%$ glycerol was added, and the protein was stored at $-80^{\circ} \mathrm{C}$.

\section{Preparation of fluorescently labeled $\alpha$-Syn ${ }^{\text {PFF }}$}

To generate $\alpha$-Syn ${ }^{\text {PFF-AF488 }}, 760 \mu \mathrm{M}$ freshly purified $\alpha$-synuclein monomers were incubated with $40 \mu \mathrm{M}$ labeled $\alpha$-synuclein-AF488 in $40 \mathrm{mM} \mathrm{KPi}$ and $50 \mathrm{mM} \mathrm{KCl}, \mathrm{pH} 7.5$, for $24 \mathrm{~h}$ at $37^{\circ} \mathrm{C}$ under continuous shaking using two 2-mm borosilicate glass beads (SigmaAldrich) in clear 96-well polystyrene microplates (Corning) (Giehm \& Otzen, 2010). Samples from the 96 -well plate were combined in Eppendorf tubes and collected via centrifugation at 20,000 $\mathrm{g}$ for 20 min at RT, and the pellets were washed twice with $40 \mathrm{mM} \mathrm{KPi}$ and 50 $\mathrm{mM} \mathrm{KCl}, \mathrm{pH} 7.5$, to remove smaller oligomers. After the final spin, the pellets were resuspended in $40 \mathrm{mM} \mathrm{KPi}$ and $50 \mathrm{mM} \mathrm{KCl}, \mathrm{pH} 7.5$, and sonicated $3 \times 5$ s on ice with an amplitude of $50 \%$. The concentration of fibrils was determined by incubating a small aliquot of $\alpha$-syn ${ }^{\text {PFF- }}$ AF488 in $8 \mathrm{M}$ urea and $20 \mathrm{mM}$ Tris, $\mathrm{pH} 7.5$, measuring the absorbance at $280 \mathrm{~nm}$ and calculating the concentration with the extinction coefficient of 5,960 liters mol ${ }^{-1} \mathrm{~cm}^{-1}$. Aliquots were taken and stored at $-80^{\circ} \mathrm{C}$

\section{Thioflavin T fluorescence and FP measurements}

Freshly purified $\alpha$-synuclein monomers (concentrations provided in the respective figure legends) were incubated with $10 \mu \mathrm{M}$ thioflavin T (ThT; Sigma-Aldrich) in $40 \mathrm{mM} \mathrm{KPi}$ and $50 \mathrm{mM} \mathrm{KCl}$, pH 7.5, at $37^{\circ} \mathrm{C}$ and two $2-\mathrm{mm}$ borosilicate glass beads (Sigma-Aldrich) in the absence or presence of poly $\mathrm{P}_{14}$ or poly $\mathrm{P}_{300}$ (given in $\mathrm{P}_{\mathrm{i}}$ units). For ThT measurements, the samples were pipetted into black 96-well polystyrene microplates with clear bottoms (Greiners). ThT fluorescence was detected in 10-min intervals using a Synergy HTX MultiMode Microplate Reader (Biotec) using an excitation of 440 $\mathrm{nm}$, emission of $485 \mathrm{~nm}$, and a gain of 35. To monitor the binding of polyP to $\alpha$-synuclein during fibril formation, the samples were pipetted into 96-well polystyrene microplates with clear bottoms (Greiners). FP was measured in a Tecan Infinite M1000 microplate reader, using an excitation of $635 \mathrm{~nm}$ and an emission of $675 \mathrm{~nm}$. Measurements were taken in 10-min intervals.

\section{PolyP binding and competition assays using anisotropy measurements}

Anisotropy measurements were conducted in the Varian Cary Eclipse Fluorescence Spectrophotometer, using an excitation of $640 \mathrm{~nm}$ and an emission of $675 \mathrm{~nm}$ (photomultiplier tube value set between 50 and 100). Samples containing $50 \mu \mathrm{M}$ polyP-AF647 in $40 \mathrm{mM}$ KPi and $50 \mathrm{mM}$ $\mathrm{KCl}, \mathrm{pH} 7.5$, at $37^{\circ} \mathrm{C}$. At the indicated time points, $30 \mu \mathrm{M}$ of $\alpha$-synuclein monomers or $\alpha$-synuclein fibrils were added and anisotropy was further monitored over time. For competition experiments, $\alpha$-synuclein fibrils were formed in the presence of poly $\mathrm{P}_{300-\mathrm{AF647}}$ as before. At 
defined time points, unlabeled poly $\mathrm{P}_{14}$ or poly $\mathrm{P}_{300}$ was added, and the anisotropy signal was monitored over time.

\section{Negative stain of fibrils and TEM analysis}

To form fibrils for TEM analysis, $300 \mu \mathrm{M}$ freshly prepared $\alpha$ synuclein monomers were incubated either in the absence of polyP (i.e., $\alpha$-syn ${ }^{\text {alone }}$ ) or in the presence of $7.5 \mathrm{mM}$ (per Pi) poly $\mathrm{P}_{300}$ (i.e., $\alpha$-syn ${ }^{\text {polyP }}$ ) for $24 \mathrm{~h}$ at $37^{\circ} \mathrm{C}$ with $2-\mathrm{mm}$ borosilicate glass beads under continuous shaking. Alpha-syn ${ }^{\text {alone }}$ fibrils were then either left untreated or were incubated with $7.5 \mathrm{mM}$ poly $\mathrm{P}_{300}$ for $20 \mathrm{~min}$ (i.e., $\alpha$-syn ${ }^{\text {alone }} \rightarrow$ polyP). The samples were negatively stained with $0.75 \%$ uranyl formate $(\mathrm{pH}$ 5.5-6.0) on thin amorphous carbonlayered 400-mesh copper grids (Pelco) in a procedure according to Ohi et al (2004). Briefly, $5 \mu \mathrm{l}$ of the sample was applied onto the grid and left for 3 min before removing it with Whatman paper. The

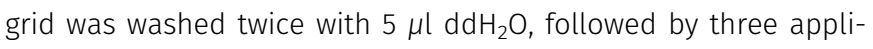
cations of $5 \mu \mathrm{l}$ uranyl formate. The liquid was removed using a vacuum. The grids were imaged at RT using a Fei Tecnai $12 \mathrm{mi}-$ croscope operating at $120 \mathrm{kV}$. Images were acquired on a US 4,000 CCD camera at $66873 \times$ resulting in a sampling of $2.21 \AA /$ pixel. About 30-40 individual $\alpha$-synuclein filaments were selected across 10 micrographs of each sample and the filament widths were determined using the micrograph dimensions as a reference. Pixel widths were converted into angstroms using the program ImageJ.

\section{X-ray fiber diffraction}

$\alpha$-synuclein fibrils were grown with and without polyP as described above. Before orientation for diffraction, 1-2 $\mathrm{ml}$ of a solution containing $100 \mu \mathrm{M} \alpha$-synuclein fibrils were washed three times with $10 \mathrm{mM}$ Tris, $\mathrm{pH}$ 7. The fibrils were then pelleted by centrifugation (15,000g, $5 \mathrm{~min})$. The supernatant was removed and the pellet was resuspended in 5-10 $\mu \mathrm{l} 10 \mathrm{mM}$ Tris, $\mathrm{pH}$ 7.0. $5 \mu \mathrm{l}$ of the fibril pellet was then placed between two fire-polished silanized glass capillaries and oriented by air-drying. The glass capillaries with the aligned fibrils were mounted on a brass pin. Diffraction patterns were recorded using $1.13 \AA$ X-rays produced by a 21-ID-D beamline, Argonne Photon Source. All patterns were collected at a distance of $200 \mathrm{~mm}$ and analyzed using the Adxv software package (Arvai, 2015).

\section{PolyP concentration determination using the molybdate assay}

$40 \mu \mathrm{M}$ of $\alpha$-synuclein monomers or fibrils, prepared in $40 \mathrm{mM}$ Hepes, $\mathrm{pH} 7.5$, and $50 \mathrm{mM} \mathrm{KCl}$, were incubated with the indicated concentrations of poly $\mathrm{P}_{300}$ for $10 \mathrm{~min}$ at RT in a clear 96-well plate (Corning). The samples were either used directly or spun down at $20,000 \mathrm{~g}$ for $20 \mathrm{~min}$ at RT to remove any unbound polyP. The pellets were resuspended in $40 \mathrm{mM}$ Hepes $(\mathrm{pH} 7.5)$ and $50 \mathrm{mM} \mathrm{KCl}$. Next, $8 \mu \mathrm{g} / \mathrm{ml}$ Saccharomyces cerevisiae exopolyphosphate (ScPPX) and $1 \mathrm{mM} \mathrm{MgCl} 2$ was added to each sample and the incubation was continued for $105 \mathrm{~min}$ (for spin down) or $120 \mathrm{~min}$ (for titration) at RT. To stop the reaction and detect $\mathrm{P}_{\mathrm{i}}, 25 \mu \mathrm{l}$ of a detection solution containing $600 \mathrm{mM} \mathrm{H}_{2} \mathrm{SO}_{4}$, $88 \mathrm{mM}$ ascorbic acid, $0.6 \mathrm{mM}$ potassium antimony tartrate, and $2.4 \mathrm{mM}$ ammonium heptamolybdate was added (Christ \& Blank, 2018; Pokhrel et al, 2019). The reactions were developed for $30 \mathrm{~min}$. Then, the precipitated proteins were resolubilized with $100 \mu \mathrm{l}$ of $1 \mathrm{M} \mathrm{NaOH}$, and the absorbance was measured at $882 \mathrm{~nm}$ using a Tecan M1000 plate reader. The free phosphate concentration was determined with a standard curve of sodium phosphate, which was prepared in parallel with each experiment. After the spun down, the phosphate measured in the supernatant was considered free, and the phosphate measured in the pellet was considered bound and unprotected. The bound and protected fraction of phosphate was calculated as total polyphosphate (measured in parallel) minus supernatant phosphate minus pellet phosphate.

\section{Cell culture experiments and microscopy}

Human neuroblastoma cells, SH-SY5Y cells (ATCC CRL-2266), were cultured in Dulbecco's Modified Eagle Medium/Nutrient Mixture F-12 (Thermo Fisher Scientific) medium supplemented with $10 \%$ (vol/vol) heat-inactivated fetal bovine serum (Sigma-Aldrich), $1 \%$ (wt/vol) penicillin/streptomycin (Life Technologies) at $37^{\circ} \mathrm{C}$, and $5 \%$ $\mathrm{CO}_{2}$. The media was changed every 2-3 $\mathrm{d}$ and the cells were split 1-2 times per week. For microscopy experiments, 60,000 cells $/ \mathrm{ml}$ were seeded in eight-well Nunc Lab-Tek II Chambered Coverglass (Thermo Fisher Scientific) and differentiated for 5-7 d by adding 10 $\mu \mathrm{M}$ all-trans retinoic acid (Sigma-Aldrich) every other day. The differentiated cells were incubated with $3 \mu \mathrm{M} \alpha$-syn ${ }^{\text {PFF-AF488 in the }}$ presence or absence of the indicated concentrations of polyP at either $37^{\circ} \mathrm{C}$ or $4^{\circ} \mathrm{C}$ for the indicated times. Before the imaging, the media was exchanged to DMEM/F12 without phenol red (Thermo Fisher Scientific), supplemented with 10\% (vol/vol) heatinactivated fetal bovine serum (Sigma-Aldrich), and 1\% (wt/vol) penicillin/streptomycin (Life Technologies). The cells were imaged using a Leica SP8 high-resolution microscope. To distinguish between the inside and outside signals, the cells were treated the same way, but $0.05 \%$ of the membrane-impermeable dye trypan blue was used for $15 \mathrm{~s}$ before the imaging to quench extracellular fluorescence (Karpowicz et al, 2017). To enrich for endogenous polyP, SH-SY5Y cells were seeded and differentiated as described above. Once differentiated, the cells were either left untreated or incubated with $250 \mu \mathrm{M}$ polyP-AF647 (per Pi) for $24 \mathrm{~h}$. Subsequently, fresh medium was added to the cells for $6 \mathrm{~h}$. Afterwards, the cells were incubated with $3 \mu \mathrm{M} \alpha$-Syn ${ }^{\text {PFF-AF488 }}$ for $24 \mathrm{~h}$. As before, the media was changed before imaging and the cells were imaged using Leica SP8 high-resolution microscope. To test the influence of polyP during the $\alpha$-Syn ${ }^{\text {PFF-AF488 }}$ uptake, differentiated SH-SY5Y cells were incubated with $3 \mu \mathrm{M} \alpha-$ Syn $^{\text {PFF-AF } 488}$ at $37^{\circ}$ C. After 2, 4, or 6 h, 250 $\mu \mathrm{M}$ polyP-AF647 was added to the cells. The cells were imaged at time points $1,2.5,5,7$, and $24 \mathrm{~h}$. To test for co-localization of $\alpha$-syn PFF-AF488 and polyP-AF647, the cells were incubated with $3 \mu \mathrm{M} \alpha-$ syn $^{\text {PFF-AF488 }}$ at $37^{\circ} \mathrm{C}$. After $6 \mathrm{~h}, 250 \mu \mathrm{M}$ polyP-AF647 was added and the cells were imaged after $7 \mathrm{~h}$. To monitor the influence of polyP on the uptake of TAT, differentiated SH-SY5Y cells were incubated with $5 \mu \mathrm{M}$ TATTAMRA (AnaSpec) and $3 \mu \mathrm{M} \alpha$-Syn ${ }^{\text {PFF-AF488 }}$ either in the presence or in the absence of $250 \mu \mathrm{M}$ polyP. After $3 \mathrm{~h}$ of incubation, the cells were imaged with a Leica SP8 high-resolution microscope.

\section{Statistics}

Two-tailed $t$ tests were performed when two groups were compared. One-way ANOVA was performed when comparing more than 
two groups. P-values under 0.05 were considered significant. All data in bar charts are displayed as mean \pm SD. Replicate numbers (n) are listed in each figure legend. Prism 7.04 (GraphPad) was used to perform statistical analysis. ANOVA analysis in Fig 2B shows an $\mathrm{F}$ value of 8.435 and a degree of freedom of 3 .

\section{Data Availability}

The datasets generated are available from the corresponding author upon request.

\section{Supplementary Information}

Supplementary Information is available at https://doi.org/10.26508/lsa. 201900486.

\section{Acknowledgements}

Defined-length polyP chains were kindly provided by T. Shiba (Regenetiss) and the Morrissey lab. We thank the American Type Culture Collection for providing us with SH-SY5Y cells. This work was funded by the NIH grants GM122506 to U Jakob and a grant from the American Parkinson Disease Association to MI Ivanova and A Sutter. I Lempart was funded by a scholarship from the Boehringer Ingelheim Foundation.

\section{Author Contribution}

J Lempart: conceptualization, data curation, formal analysis, supervision, funding acquisition, project administration, and writing-original draft, review, and editing.

E Tse: data curation, formal analysis, investigation, and methodology. JA Lauer: investigation and methodology.

MI Ivanova: data curation, formal analysis, and supervision.

A Sutter: data curation, formal analysis, investigation, and methodology. N Yoo: data curation, formal analysis, investigation, and methodology. P Huettemann: investigation and methodology.

D Southworth: conceptualization, data curation, formal analysis, and project administration.

U Jakob: conceptualization, supervision, funding acquisition, investigation, project administration, and writing-review and editing.

\section{Conflict of Interest Statement}

The authors declare that they have no conflict of interest.

\section{References}

Angelova PR, Iversen KZ, Teschemacher AG, Kasparov S, Gourine AV, Abramov AY (2018) Signal transduction in astrocytes: Localization and release of inorganic polyphosphate. Glia 66: 2126-2136. doi:10.1002/glia.23466

Arvai A (2015) A Program to Display X-Ray Diffraction Images. Available at: http://www.scripps.edu/tainer/arvai/adxv.html.
Chen SW, Drakulic S, Deas E, Ouberai M, Aprile FA, Arranz R, Ness S, Roodveldt C, Guilliams T, De-Genst EJ, et al (2015) Structural characterization of toxic oligomers that are kinetically trapped during alpha-synuclein fibril formation. Proc Natl Acad Sci U S A 112: E1994-E2003. doi:10.1073/ pnas.1421204112

Choi SH, Collins JN, Smith SA, Davis-Harrison RL, Rienstra CM, Morrissey JH (2010) Phosphoramidate end labeling of inorganic polyphosphates: Facile manipulation of polyphosphate for investigating and modulating its biological activities. Biochemistry 49: 9935-9941. doi:10.1021/bi1014437

Christ JJ, Blank LM (2018) Enzymatic quantification and length determination of polyphosphate down to a chain length of two. Anal Biochem 548: 82-90. doi:10.1016/j.ab.2018.02.018

Cohlberg JA, Li J, Uversky VN, Fink AL (2002) Heparin and other glycosaminoglycans stimulate the formation of amyloid fibrils from alpha-synuclein in vitro. Biochemistry 41: 1502-1511. doi:10.1021/ bi011711s

Conway KA, Harper JD, Lansbury PT Jr (2000a) Fibrils formed in vitro from alpha-synuclein and two mutant forms linked to Parkinson's disease are typical amyloid. Biochemistry 39: 2552-2563. doi:10.1021/bi991447r

Conway KA, Lee S), Rochet JC, Ding TT, Williamson RE, Lansbury PT Jr (2000b) Acceleration of oligomerization, not fibrillization, is a shared property of both alpha-synuclein mutations linked to early-onset Parkinson's disease: Implications for pathogenesis and therapy. Proc Natl Acad Sci U S A 97: 571-576. doi:10.1073/pnas.97.2.571

Cremers CM, Knoefler D, Gates S, Martin N, Dahl JU, Lempart J, Xie L, Chapman MR, Galvan V, Southworth DR, et al (2016) Polyphosphate: A conserved modifier of amyloidogenic processes. Mol Cell 63: 768-780. doi:10.1016/j.molcel.2016.07.016

Damier P, Hirsch EC, Agid Y, Graybiel AM (1999) The substantia nigra of the human brain. II. Patterns of loss of dopamine-containing neurons in Parkinson's disease. Brain 122: 1437-1448. doi:10.1093/brain/122.8.1437

Danzer KM, Kranich LR, Ruf WP, Cagsal-Getkin O, Winslow AR, Zhu L, Vanderburg CR, McLean PJ (2012) Exosomal cell-to-cell transmission of alpha synuclein oligomers. Mol Neurodegener 7: 42. doi:10.1186/ 1750-1326-7-42

Danzer KM, Krebs SK, Wolff M, Birk G, Hengerer B (2009) Seeding induced by alpha-synuclein oligomers provides evidence for spreading of alphasynuclein pathology. J Neurochem 111: 192-203. doi:10.1111/j.14714159.2009.06324.X

de Lau LM, Giesbergen PC, de Rijk MC, Hofman A, Koudstaal PJ, Breteler MM (2004) Incidence of parkinsonism and Parkinson disease in a general population: The Rotterdam study. Neurology 63: 1240-1244. doi:10.1212/01.wnl.0000140706.52798.be

Desplats P, Lee HJ, Bae EJ, Patrick C, Rockenstein E, Crews L, Spencer B, Masliah E, Lee SJ (2009) Inclusion formation and neuronal cell death through neuron-to-neuron transmission of alpha-synuclein. Proc Natl Acad Sci U S A 106: 13010-13015. doi:10.1073/pnas.0903691106

Domert J, Sackmann C, Severinsson E, Agholme L, Bergstrom J, Ingelsson M, Hallbeck M (2016) Aggregated alpha-synuclein transfer efficiently between cultured human neuron-like cells and localize to lysosomes. PLoS One 11: e0168700. doi:10.1371/journal.pone.0168700

El-Agnaf OMA, Irvine GB (2000) Review: Formation and properties of amyloidlike fibrils derived from $\alpha$-synuclein and related proteins. I Struct Biol 130: 300-309. doi:10.1006/jsbi.2000.4262

Fakhree MAA, Nolten IS, Blum C, Claessens M (2018) Different conformational subensembles of the intrinsically disordered protein alpha-synuclein in cells. J Phys Chem Lett 9: 1249-1253. doi:10.1021/acs.jpclett.8b00092

Giehm L, Otzen DE (2010) Strategies to increase the reproducibility of protein fibrillization in plate reader assays. Anal Biochem 400: 270-281. doi:10.1016/j.ab.2010.02.001

Goedert M (2001) Alpha-synuclein and neurodegenerative diseases. Nat Rev Neurosci 2: 492-501. doi:10.1038/35081564 
Goldberg MS, Lansbury PT, Jr (2000) Is there a cause-and-effect relationship between $\alpha$-synuclein fibrillization and Parkinson's disease? Nat Cell Biol 2: E115-E119. doi:10.1038/35017124

Grey M, Linse S, Nilsson H, Brundin P, Sparr E (2011) Membrane interaction of alpha-synuclein in different aggregation states. J Parkinsons Dis 1: 359-371. doi:10.3233/JPD-2011-11067

Guerrero-Ferreira R, Taylor NM, Mona D, Ringler P, Lauer ME, Riek R, Britschgi M, Stahlberg H (2018) Cryo-EM structure of alpha-synuclein fibrils. Elife 7: e36402. doi:10.7554/eLife.36402

Gustafsson G, Loov C, Persson E, Lazaro DF, Takeda S, Bergstrom J, Erlandsson A, Sehlin D, Balaj L, Gyorgy B, et al (2018) Secretion and uptake of alpha-synuclein via extracellular vesicles in cultured cells. Cell Mol Neurobiol 38: 1539-1550. doi:10.1007/s10571-018-0622-5

Hansen C, Angot E, Bergstrom AL, Steiner JA, Pieri L, Paul G, Outeiro TF, Melki R, Kallunki P, Fog K, et al (2011) alpha-Synuclein propagates from mouse brain to grafted dopaminergic neurons and seeds aggregation in cultured human cells. J Clin Invest 121: 715-725. doi:10.1172/JCI43366

Holmes BB, DeVos SL, Kfoury N, Li M, Jacks R, Yanamandra K, Ouidja MO, Brodsky FM, Marasa J, Bagchi DP, et al (2013) Heparan sulfate proteoglycans mediate internalization and propagation of specific proteopathic seeds. Proc Natl Acad Sci U S A 110: E3138-E3147. doi:10.1073/pnas.1301440110

Holmstrom KM, Marina N, Baev AY, Wood NW, Gourine AV, Abramov AY (2013) Signalling properties of inorganic polyphosphate in the mammalian brain. Nat Commun 4: 1362. doi:10.1038/ncomms2364

Ihse E, Yamakado H, van Wijk XM, Lawrence R, Esko JD, Masliah E (2017) Cellular internalization of alpha-synuclein aggregates by cell surface heparan sulfate depends on aggregate conformation and cell type. Sci Rep 7: 9008. doi:10.1038/s41598-017-08720-5

Jain N, Bhasne K, Hemaswasthi M, Mukhopadhyay S (2013) Structural and dynamical insights into the membrane-bound alpha-synuclein. PLOS One 8: e83752. doi:10.1371/journal.pone.0083752

Kaplan IM, Wadia JS, Dowdy SF (2005) Cationic TAT peptide transduction domain enters cells by macropinocytosis. I Control Release 102: 247-253. doi:10.1016/j.jconrel.2004.10.018

Karpowicz RJ, Jr, Haney CM, Mihaila TS, Sandler RM, Petersson EJ, Lee VM (2017) Selective imaging of internalized proteopathic alpha-synuclein seeds in primary neurons reveals mechanistic insight into transmission of synucleinopathies. J Biol Chem 292: 13482-13497. doi:10.1074/ jbc.M117.780296

Krishnan S, Chi EY, Wood SJ, Kendrick BS, Li C, Garzon-Rodriguez W, Wypych J, Randolph TW, Narhi LO, Biere AL, et al (2003) Oxidative dimer formation is the critical rate-limiting step for Parkinson's disease alpha-synuclein fibrillogenesis. Biochemistry 42: 829-837. doi:10.1021/ bi026528t

Kumble KD, Kornberg A (1995) Inorganic polyphosphate in mammalian cells and tissues. J Biol Chem 270: 5818-5822. doi:10.1074/jbc.270.11.5818

Lashuel HA, Petre BM, Wall J, Simon M, Nowak RJ, Walz T, Lansbury PT, Jr (2002) Alpha-synuclein, especially the Parkinson's disease-associated mutants, forms pore-like annular and tubular protofibrils. J Mol Biol 322: 1089-1102. doi:10.1016/s0022-2836(02)00735-0

Lee HJ, Suk JE, Patrick C, Bae EJ, Cho JH, Rho S, Hwang D, Masliah E, Lee SJ (2010) Direct transfer of alpha-synuclein from neuron to astroglia causes inflammatory responses in synucleinopathies. J Biol Chem 285: 9262-9272. doi:10.1074/jbc.M109.081125

LeVine H 3rd (1999) Quantification of beta-sheet amyloid fibril structures with thioflavin T. Methods Enzymol 309: 274-284. doi:10.1016/s00766879(99)09020-5

Li JY, Englund E, Holton JL, Soulet D, Hagell P, Lees AJ, Lashley T, Quinn NP, Rehncrona S, Bjorklund A, et al (2008) Lewy bodies in grafted neurons in subjects with Parkinson's disease suggest host-to-graft disease propagation. Nat Med 14: 501-503. doi:10.1038/nm1746
Lorenz B, Munkner J, Oliveira MP, Kuusksalu A, Leitao JM, Muller WE, Schroder HC (1997) Changes in metabolism of inorganic polyphosphate in rat tissues and human cells during development and apoptosis. Biochim Biophys Acta 1335: 51-60. doi:10.1016/s0304-4165(96)00121-3

Luk KC, Kehm VM, Zhang B, O'Brien P, Trojanowski JQ, Lee VM (2012) Intracerebral inoculation of pathological alpha-synuclein initiates a rapidly progressive neurodegenerative alpha-synucleinopathy in mice. J Exp Med 209: 975-986. doi:10.1084/jem.20112457

Luk KC, Song C, O'Brien P, Stieber A, Branch JR, Brunden KR, Trojanowski JQ, Lee VM (2009) Exogenous alpha-synuclein fibrils seed the formation of Lewy body-like intracellular inclusions in cultured cells. Proc Natl Acad Sci U S A 106: 20051-20056. doi:10.1073/pnas.0908005106

Luth ES, Stavrovskaya IG, Bartels T, Kristal BS, Selkoe DJ (2014) Soluble, prefibrillar alpha-synuclein oligomers promote complex I-dependent, Ca2+-induced mitochondrial dysfunction. J Biol Chem 289: 21490-21507. doi:10.1074/jbc.M113.545749

Mehra S, Ghosh D, Kumar R, Mondal M, Gadhe LG, Das S, Anoop A, Jha NN, Jacob RS, Chatterjee D, et al (2018) Glycosaminoglycans have variable effects on alpha-synuclein aggregation and differentially affect the activities of the resulting amyloid fibrils. J Biol Chem 293: 12975-12991. doi:10.1074/jbc.RA118.004267

Mullan A, Quinn JP, McGrath JW (2002) A nonradioactive method for the assay of polyphosphate kinase activity and its application in the study of polyphosphate metabolism in Burkholderia cepacia. Anal Biochem 308: 294-299. doi:10.1016/s0003-2697(02)00249-x

Muller WEG, Wang S, Ackermann M, Neufurth M, Steffen R, Mecja E, Munoz-Espi R, Feng Q, Schroder HC, Wang X (2017) Rebalancing betaamyloid-induced decrease of ATP level by amorphous nano/micro polyphosphate: Suppression of the neurotoxic effect of amyloid betaprotein fragment 25-35. Int J Mol Sci 18: E2154. doi:10.3390/ijms18102154

Munishkina LA, Fink AL, Uversky VN (2009) Accelerated fibrillation of alphasynuclein induced by the combined action of macromolecular crowding and factors inducing partial folding. Curr Alzheimer Res 6 : 252-260. doi:10.2174/156720509788486491

Nakase I, Niwa M, Takeuchi T, Sonomura K, Kawabata N, Koike Y, Takehashi M, Tanaka S, Ueda K, Simpson JC, et al (2004) Cellular uptake of argininerich peptides: Roles for macropinocytosis and actin rearrangement. Mol Ther 10: 1011-1022. doi:10.1016/j.ymthe.2004.08.010

Ohi M, Li Y, Cheng Y, Walz T (2004) Negative staining and image classification: Powerful tools in modern electron microscopy. Biol Proced Online 6: 23-34. doi:10.1251/bpo70

Paumier KL, Luk KC, Manfredsson FP, Kanaan NM, Lipton JW, Collier TJ, SteeceCollier K, Kemp CJ, Celano S, Schulz E, et al (2015) Intrastriatal injection of pre-formed mouse alpha-synuclein fibrils into rats triggers alphasynuclein pathology and bilateral nigrostriatal degeneration. Neurobiol Dis 82: 185-199. doi:10.1016/j.nbd.2015.06.003

Pokhrel A, Lingo JC, Wolschendorf F, Gray MJ (2019) Assaying for inorganic polyphosphate in bacteria. J Vis Exp. doi:10.3791/58818

Reyes JF, Olsson TT, Lamberts JT, Devine MJ, Kunath T, Brundin P (2015) A cell culture model for monitoring alpha-synuclein cell-to-cell transfer. Neurobiol Dis 77: 266-275. doi:10.1016/j.nbd.2014.07.003

Reynolds NP, Soragni A, Rabe M, Verdes D, Liverani E, Handschin S, Riek R, Seeger S (2011) Mechanism of membrane interaction and disruption by alpha-synuclein. J Am Chem Soc 133: 19366-19375. doi:10.1021/ ja2029848

Rinne JO, Rummukainen J, Paljarvi L, Rinne UK (1989) Dementia in Parkinson's disease is related to neuronal loss in the medial substantia nigra. Ann Neurol 26: 47-50. doi:10.1002/ana.410260107

Roberts HL, Brown DR (2015) Seeking a mechanism for the toxicity of oligomeric alpha-synuclein. Biomolecules 5: 282-305. doi:10.3390/ biom5020282

Rodriguez L, Marano MM, Tandon A (2018) Import and export of misfolded alpha-synuclein. Front Neurosci 12: 344. doi:10.3389/fnins.2018.00344 
Rossi AM, Taylor CW (2011) Analysis of protein-ligand interactions by fluorescence polarization. Nat Protoc 6: 365-387. doi:10.1038/ nprot.2011.305

Rostami J, Holmqvist S, Lindstrom V, Sigvardson J, Westermark GT, Ingelsson M, Bergstrom J, Roybon L, Erlandsson A (2017) Human astrocytes transfer aggregated alpha-synuclein via tunneling nanotubes. J Neurosci 37: 11835-11853. doi:10.1523/JNEUROSCI.0983-17.2017

Shoffner SK, Schnell S (2016) Estimation of the lag time in a subsequent monomer addition model for fibril elongation. Phys Chem Chem Phys 18: 21259-21268. doi:10.1039/c5cp07845h

Shults CW (2006) Lewy bodies. Proc Natl Acad Sci U S A 103: 1661-1668. doi:10.1073/pnas.0509567103

Sidhu A, Segers-Nolten I, Raussens V, Claessens MM, Subramaniam V (2017) Distinct mechanisms determine alpha-synuclein fibril morphology during growth and maturation. ACS Chem Neurosci 8: 538-547. doi:10.1021/acschemneuro.6b00287

Tsigelny IF, Sharikov Y, Wrasidlo W, Gonzalez T, Desplats PA, Crews L, Spencer B, Masliah E (2012) Role of alpha-synuclein penetration into the membrane in the mechanisms of oligomer pore formation. FEBS I 279: 1000-1013. doi:10.1111/j.1742-4658.2012.08489.x

van Rooijen BD, Claessens MM, Subramaniam V (2008) Membrane binding of oligomeric alpha-synuclein depends on bilayer charge and packing. FEBS Lett 582: 3788-3792. doi:10.1016/j.febslet.2008.10.009

van Rooijen BD, Claessens MM, Subramaniam V (2009) Lipid bilayer disruption by oligomeric alpha-synuclein depends on bilayer charge and accessibility of the hydrophobic core. Biochim Biophys Acta 1788: 1271-1278. doi:10.1016/j.bbamem.2009.03.010

Volpicelli-Daley LA, Luk KC, Patel TP, Tanik SA, Riddle DM, Stieber A, Meaney DF, Trojanowski JQ, Lee VM (2011) Exogenous alpha-synuclein fibrils induce Lewy body pathology leading to synaptic dysfunction and neuron death. Neuron 72: 57-71. doi:10.1016/j.neuron.2011.08.033

Wadia JS, Stan RV, Dowdy SF (2004) Transducible TAT-HA fusogenic peptide enhances escape of TAT-fusion proteins after lipid raft macropinocytosis. Nat Med 10: 310-315. doi:10.1038/nm996

Winner B, Jappelli R, Maji SK, Desplats PA, Boyer L, Aigner S, Hetzer C, Loher T, Vilar M, Campioni S, et al (2011) In vivo demonstration that alphasynuclein oligomers are toxic. Proc Natl Acad Sci U S A 108: 4194-4199. doi:10.1073/pnas.1100976108

Wood SJ, Wypych J, Steavenson S, Louis JC, Citron M, Biere AL (1999) alphasynuclein fibrillogenesis is nucleation-dependent. Implications for the pathogenesis of Parkinson's disease. J Biol Chem 274: 19509-19512. doi:10.1074/jbc.274.28.19509

Wurst H, Kornberg A (1994) A soluble exopolyphosphatase of Saccharomyces cerevisiae. Purification and characterization. I Biol Chem 269: 10996-11001.

Yoo NG, Dogra S, Meinen BA, Tse E, Haefliger J, Southworth DR, Gray MJ, Dahl JU, Jakob U (2018) Polyphosphate stabilizes protein unfolding intermediates as soluble amyloid-like oligomers. J Mol Biol 430: 4195-4208. doi:10.1016/j.jmb.2018.08.016

Zhu M, Li J, Fink AL (2003) The association of alpha-synuclein with membranes affects bilayer structure, stability, and fibril formation. J Biol Chem 278: 40186-40197. doi:10.1074/jbc.M305326200

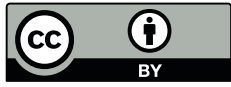

License: This article is available under a Creative Commons License (Attribution 4.0 International, as described at https://creativecommons.org/ licenses/by/4.0/). 